\title{
Regulation of cell proliferation and migration in glioblastoma: new therapeutic approach
}

\section{Yangjin Kim*}

Department of Mathematics, Konkuk University, Seoul, South Korea

\section{Edited by:}

Katarzyna A. Rejniak, H. Lee Moffitt

Cancer Center and Research Institute, USA

\section{Reviewed by:}

Andrea Hawkins-Daarud, University of Washington, USA

Xuefeng Gao, Center of Cancer

Systems Biology, USA

\section{${ }^{*}$ Correspondence}

Yangjin Kim, Department of

Mathematics, 120 Neungdong-ro,

Gwangjin-gu, Seoul, 143-701, South

Korea.

e-mail: ahyouhappy@konkuk.ac.kr
Glioblastoma is the most aggressive brain cancer with the poor survival rate. A microRNA, miR-451, and its downstream molecules, CAB39/LKB1/STRAD/AMPK, are known to play a critical role in regulating a biochemical balance between rapid proliferation and invasion in the presence of metabolic stress in microenvironment. We develop a novel multi-scale mathematical model where cell migration and proliferation are controlled through a core intracellular control system (miR-451-AMPK complex) in response to glucose availability and physical constraints in the microenvironment. Tumor cells are modeled individually and proliferation and migration of those cells are regulated by the intracellular dynamics and reaction-diffusion equations of concentrations of glucose, chemoattractant, extracellular matrix, and MMPs. The model predicts that invasion patterns and rapid growth of tumor cells after conventional surgery depend on biophysical properties of cells, dynamics of the core control system, and microenvironment as well as glucose injection methods. We developed a new type of therapeutic approach: effective injection of chemoattractant to bring invasive cells back to the surgical site after initial surgery, followed by glucose injection at the same location. The model suggests that a good combination of chemoattractant and glucose injection at appropriate time frames may lead to an effective therapeutic strategy of eradicating tumor cells.

Keywords: glioblastoma, cell migration and proliferation, miR-451, AMPK, cancer invasion and therapy

\section{INTRODUCTION}

Glioblastoma multiforme (GBM) is the most common and aggressive form of primary brain tumor with the median survival time of approximately 1 year from the time of diagnosis (Demuth and Berens, 2004; Stylli et al., 2005; Jacobs et al., 2011). GBMs are characterized by rapid proliferation and aggressive invasion into surrounding normal brain tissue, which leads to inevitable recurrence after surgical resection of the primary tumor (Chintala et al., 1999). Surgery is the primary treatment method, generally followed by inefficient radiotherapy and chemotherapy. Innovative therapeutic approaches of targeting these invasive cells are needed in order to improve clinical outcome (Davis and McCarthy, 2001). Glioblastoma cells are encountered with many challenges such as hypoxia (lack of oxygen), acidity, and limited nutrient availability as tumor growth is proceeded. To keep up with rapid growth, tumor cells need to adapt to these biochemical changes in the harsh microenvironment (Godlewski et al., 2010a). In order to overcome these challenges and sustain their rapid growth, cancerous cells change their typical metabolism (oxidative phosphorylation and anaerobic glycolysis) to inefficient metabolic machinery [high levels of glucose uptake and lactate production; Warburg Effect (Warburg, 1956; Kim and Dang, 2006)].

The Krebs, or tricarboxylic acid (TCA) cycle is a main step for generating an energy source, ATP, in non-hypoxic normal cells. While this effective way of metabolism is used by differentiated cells, tumor cells favor a seemingly less effective way of metabolism, aerobic glycolysis (Heiden et al., 2009) due to production of lactic acid, and consumption of large amounts of glucose (Kim and Dang, 2006). Adapting this aerobic glycolysis (Gatenby and Gillies, 2004), cancer cells appear to have an advantage of not having to rely on oxygen for energy source in hypoxic (hostile) microenvironment (Gatenby and Gillies, 2004; Kim and Dang, 2006). Better understanding of basic mechanism of glycolysis and intracellular dynamics may provide better clinical outcomes. For example, inhibition of glycolysis may prevent drug resistance (Xu et al., 2005). Cancer cells also adapt angiogenesis and migration as a way of ensuring an adequate glucose supply (Godlewski et al., 2010a). However, appropriate intracellular responses to glucose withdrawal are a crucial component of adaptation in order to survive periods of metabolic stress and maintain viability as a tumor grows (Jones and Thompson, 2009). The 5 '-adenosine monophosphate activated protein kinase (AMPK) pathway is the major cellular sensor of energy availability (Hardie, 2007) and is activated in the presence of metabolic stress as a way of promoting glucose uptake and energy conservation (Hardie, 2007). Dysregulation of miRNAs, 22 nucleotide single-stranded non-coding RNAs (Bartel, 2009), has been associated with oncogenic activities and tumor suppressor (Esquela-Kerscher and Slack, 2006) in many cancer types, including glioblastoma where alterations in miRNA expression induces tumorigenesis (Godlewski et al., 2008; Lawler and Chiocca, 2009). For example, miR-21 promote glioma invasion by down-regulation of inhibitors of matrix metalloprotease (MMP) (Gabriely et al., 2008). In a recent paper, Godlewski et al. (2010a) found that a particular microRNA, miR-451, determines glioma cell motility and proliferation by regulating its counterpart, AMPK signaling component (CAB39/LKB1/AMPK), 
in response to various glucose levels. While normal glucose led to up-regulation of miR-451 expression and rapid cell proliferation, deprived glucose induced down-regulation of miR-451 and elevated cell migration. Godlewski et al. (2010a) also found mutual antagonism between miR-451 activity and AMPK complex levels, which was modeled using a mathematical model in Kim et al. (2011a). See Figure 1.

Invasion of glioma cells leads to treatment failure due to poor screening of invasive individual cells by the standard clinical device and difficulty in complete elimination of the migratory cells in typical brain surgery, causing tumor recurrence (Chintala et al., 1999). Many factors may contribute to glioma cell motility in the brain tissue. Extra cellular matrix (ECM) may stimulate glioma invasion in a process known as haptotaxis. Haptotactic process is suggested to be activated by pre-existing brain components and remodeling of the ECM via proteolysis (Chintala et al., 1999; Jaalinoja et al., 2000; Choe et al., 2002). Glioma cell's motility is also influenced by various chemoattractants, which include ligands of scatter factor/hepatocyte growth factor (SF/HGF) (Lamszus et al., 1998), the EGF family (Lund-Johansen et al., 1990), the TGF- $\beta$ family (Platten et al., 2001), SDF-1 (Zhou et al., 2002), and certain lipids (Young and Brocklyn, 2007). We note that other authors studied the action of HGF or scatter factor on cell migration (Tamagnone and Comoglio, 1997; Luca et al., 1999; Stella and Comoglio, 1999; Trusolino and Comoglio, 2002; Scianna et al., 2009). Beside these factors, other cell types such as microglia can also provide indirect stimulation of cell migration by secreting matrix components and chemoattractants (Watters et al., 2005). Glioma cell migration may be regulated by specific substrates and structures in the brain as well. For instance, glioma cells are also known to follow preferred dispersion paths such as white matter tracts or the basal lamina of blood vessels. Invasion patterns of glioma cells in threedimensional tumor spheroids were studied in Kim et al. (2009)

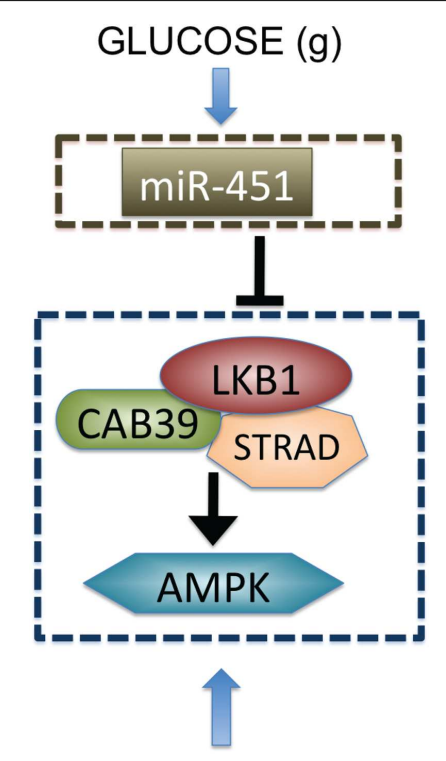

FIGURE 1 | Biological observation for regulation of miR-451-AMPK complex (Godlewski et al., 2010a). where the migration patterns exhibit a gradual shift from branching to dispersion and depend on three key parameters (cell-cell adhesion strength, haptotactic parameter, and chemotactic sensitivity). There are several publications based on a diffusion model (Swanson et al., 2003; Harpold et al., 2007).

Other authors investigated the transition between migration and proliferation using kinetic or diffusion models (Chauviere et al., 2010; Hatzikirou et al., 2010; Pham et al., 2012). A general review on hybrid models of tumor growth can be found in Rejniak and Anderson (2011). In the present paper, the detailed dynamics of a core control system (miR-451-AMPK) at each cell site is embedded in a hybrid model and is linked to extracellular glucose molecules which diffuse to brain tissue. In the hybrid model, tumor cells either migrate or proliferate in response to biochemical signals such as glucose and chemoattractants. Migratory cells are attracted to chemotactic source and secrete MMPs to degrade extracellular matrix (ECM). We show how the spatial migrating patterns of glioma cells can be controlled by the core system in the absence and presence of chemotactic source after initial surgery and explore how injection of glucose and chemoattractants could be manipulated for better therapeutic options. More importantly, we use the current model to test hypotheses on chemotaxis-glucose-driven therapy, i.e., eradicating "invisible" invasive cells after surgery. We propose that injection of chemoattractants after surgery followed by glucose injection at the tumor site would bring migratory glioma cells back to the surgical site and make them detectable by MRI, and the follow-up surgery may improve clinical outcomes by eradicating the remaining growing tumor cells.

In Section 2 we introduce a multi-scale mathematical model. In Section 3, we present the results from the hybrid model. Discussion and future work are provided in Section 4. Parameter estimation and non-dimensionalization of the model are given in Appendix.

\section{MATERIALS AND METHODS}

In this section, we introduce a multi-scale mathematical model of regulation of cell proliferation and migration in glioblastoma. We consider a brain tissue, $\Omega=[0, L]^{2}$, with glioblastoma tumor initially occupying a sphere $\Omega_{c}^{0}=\left\{x:|x|<R_{0}, R_{0}<L\right\}$, where $R_{0}$ is the initial radius of the tumor spheroid. A schematic of the hybrid model is shown in Figure 2. We first introduce the cell-mechanics part of the model.

\subsection{THE CELL-MECHANICS}

The mechanical behavior of individual cells is based on the models developed by Dallon and Othmer (2004) and Kim et al. (2007, 2011b). The forces on a cell in the model include (i) the dynamic drag forces from adhesive bonds with neighboring cells, (ii) the active forces $\mathbf{T}_{i}$ exerted on the substrate or neighboring cells and the reaction force $\left(\mathbf{M}_{j, i}\right)$, (iii) static friction force $\mathbf{S}_{j, i}$ for rigid attachment between cells or between a cell and the substrate. (See DO for a more detailed discussion of all forces involved.) The total force on the $i$ th cell is then given by

$$
\mathbf{F}_{i}=\sum_{j \in \mathcal{N}_{i}^{a}} \mathbf{M}_{j, i}+\sum_{j \in \mathcal{N}_{i}^{a}} \mathbf{T}_{i}+\sum_{j \in \mathcal{N}_{i}^{d}} \mu_{i j}\left(\mathbf{v}_{j}-\mathbf{v}_{i}\right)+\sum_{j \in \mathcal{N}_{i}^{s}} \mathbf{s}_{j, i}
$$




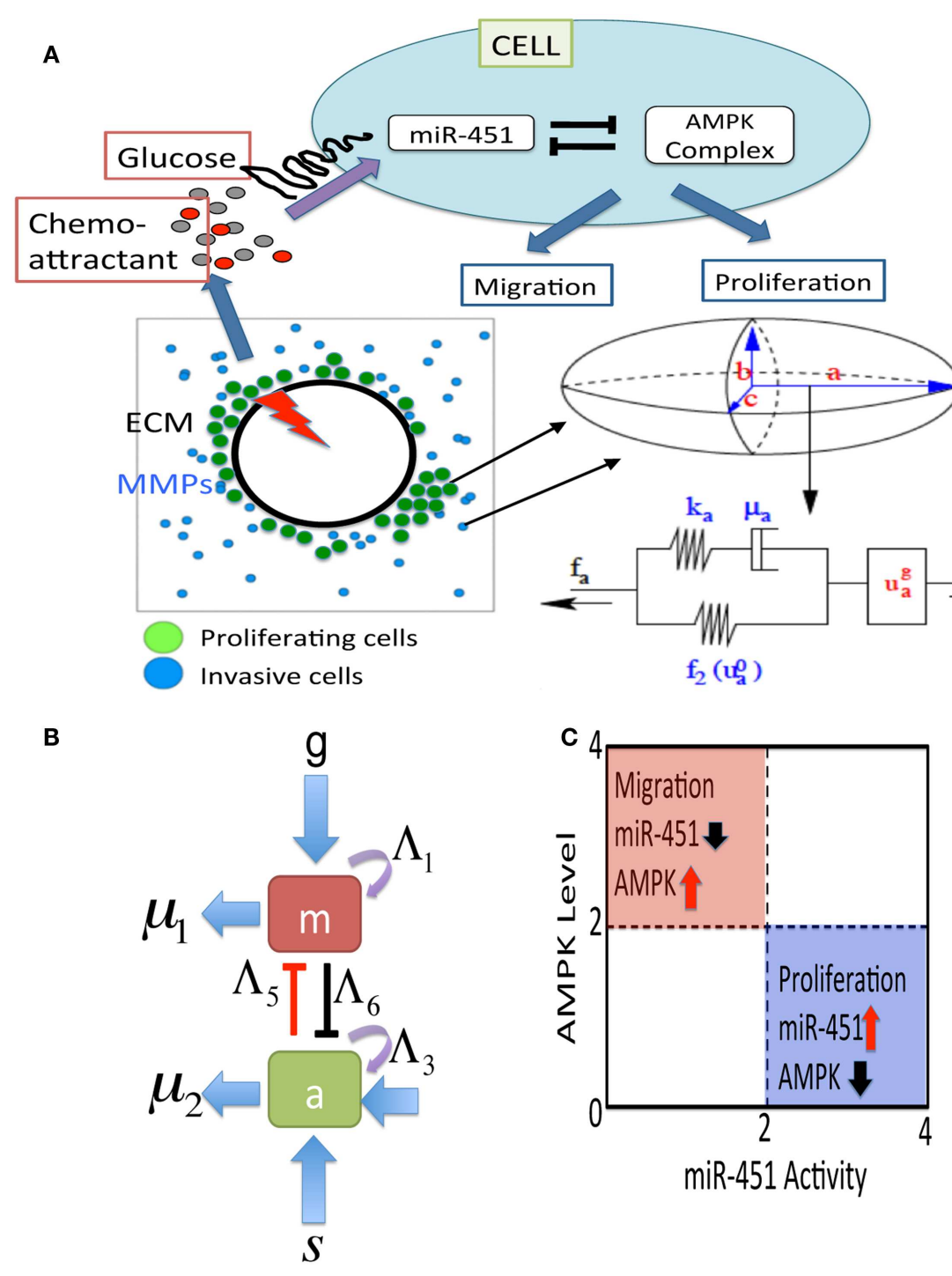

FIGURE 2 | (A) A schematic of the hybrid model for therapeutic approaches. (Top) Simplified model of the core control system (miR-451 and AMPK complex) in response to various glucose levels at a tumor cell site. The core system determines the cell fate, either proliferation or migration. Chemoattractants in the brain tissue determine the migration direction of the cell. (Bottom, Left) Model domain: some migratory cancer cells (blue) near the tumor core site are activated to become a proliferative one (green) via miR-451-AMPK regulation in response to glucose injection levels (red thunder) at the center of the tumor site.
(Bottom, right) changes in the length of the a-axis of a cell (the ellipsoid) under a given force $\left(f_{a}\right.$; arrow) consist of the passive change in the first component (a Maxwell element in parallel with a non-linear spring) and the change due to the growth $\left(u_{a}^{g}\right)$. The growth component depends on the levels of miR-451 and AMPK complex, and the force $\left(f_{a}\right)$. The mechanical and growth elements are the same along all axes.

(B) miR-451 activity and levels of its target complex (CAB39/LKB1/AMPK) were represented by " $m$ " and " $a$," respectively. (C) The migratory and proliferative regions based on miR-451 activity and AMPK levels. where $\mathcal{N}_{i}^{a}$ denotes the neighbors of $i$, including the substrate, upon which it can exert traction, $\mathcal{N}_{i}^{d}$ is the set of "cells" (which includes substrate and extracellular matrix) that interact with $i$ via a frictional force, and $\mathcal{N}_{i}^{s}$ denotes the set of cells that statically bind to cell $i$. These force balance equations allow us to calculate all forces involved and track down locations of all cells in addition to biophysical response of the cells.

There are two different kinds of cells involved-proliferative one and motile one. The basic mechanical scheme of cell proliferation is modeled as in Kim et al. (2007) and the basic algorithm for motile cells is introduced as in Dallon and Othmer (2004). The cells are treated as oriented ellipsoids and cytoplasm is considered as an incompressible, viscoelastic solid. When growth is off, their volume is constant under all deformations. However, growth component $\left(u_{g}^{a}\right)$ is included in series the active response and the passive forces. (See Figure 2A.) We use the multiplicative form of the growth rate function for the $i$-th axis given by

$$
\left(u_{i}^{g}\right)^{\prime}=f(\sigma) P(M, A)
$$


where $\sigma$ is the force acting on the cell and $P$ is a function of the miR-451 activity $(M)$ and AMPK levels $(A)$. The growth function $f(\sigma)$ is defined so that cells can grow under sufficiently small tensile and compressive forces (Kim et al., 2007, 2011b). The relationship between growth and stresses are complex and further detailed modeling work is needed. Cell proliferation may depend on up- or down-regulation of intracellular players that control the cell cycle. In the present work, we assume that the core system determines cell proliferation, i.e., a cell proliferates when miR-451 (AMPK) is up-regulated (down-regulated) at the cell site. Then, the function $P(M, A)$ is defined as

$$
P(M, A)= \begin{cases}1 & \text { if } M>t h_{M}, A<t h_{A} \\ 0 & \text { otherwise }\end{cases}
$$

where $t h_{M}$, th $h_{A}$ are threshold values of the miR-451 and AMPK levels that will be introduced in Section 2.3. The active force $\mathbf{T}_{i}$ of cell $i$ is given by

$$
\mathbf{T}_{i}=\phi\left(M_{i}\right) \frac{\nabla C}{\sqrt{K_{C}+|\nabla C|^{2}}}
$$

where $C$ is the concentration of a chemoattractant. Here, the indicator function $\phi(M)$ is given by

$$
\phi(M)= \begin{cases}r_{n} F_{0} & \begin{array}{r}
\text { if } M<t h_{M}, A>t h_{A}, \text { cell without } \\
\text { physical constraints }
\end{array} \\
0 & \text { otherwise }\end{cases}
$$

where $F_{0}$ is the basal magnitude of the active force $\left(0 \leq\left|\mathbf{T}_{i}\right| \leq F_{0}\right)$ and $r_{n}$ is a random number in $[0.8,1.2]$. Therefore, the active force is completely turned off for proliferative cells $\left(M_{i}>t h_{M}\right.$, $A<t h_{A}$ ), cells under physical constraints (a cell completely surrounded by neighboring cells), or in the absence of chemotactic signal $(\nabla C=0)$.

\subsection{REACTION-DIFFUSION}

We let $G(\mathbf{x}, t), C(\mathbf{x}, t), \rho(\mathbf{x}, t), P(\mathbf{x}, t)$ be the concentrations of glucose, a chemoattractant of glioma cells, ECM, and MMPs, respectively, at space $\mathbf{x}$ and time $t$. Governing equations of all variables are given by

$$
\begin{aligned}
\frac{\partial G}{\partial t}= & \underbrace{D_{G} \Delta G}_{\text {Diffusion }}+\underbrace{\sum_{j=1}^{N_{G}} \lambda_{\text {in }}^{G} I_{\left[t_{j}^{G}, t_{j}^{G}+\tau_{d}^{G}\right] \times \Omega_{\epsilon}}}_{\text {Injection }} \\
& +\underbrace{\lambda_{b} \eta_{1}(x, G)}_{\text {Input }}-\underbrace{\lambda_{c} \eta_{2}(x, G)}_{\text {Consumption }}-\underbrace{\mu_{G} G}_{\text {Removal }} \text { in } \Omega, \\
\frac{\partial C}{\partial t}= & \underbrace{D_{C} \Delta C}_{\text {Diffusion }}+\underbrace{\sum_{j=1}^{N_{C}} \lambda_{\text {in }}^{C} I_{\left[t_{j}^{C}, t_{j}^{C}+\tau_{d}^{C}\right] \times \Omega_{\epsilon}}}_{\text {Injection }}-\underbrace{\mu_{C} C}_{\text {Decay }} \text { in } \Omega,
\end{aligned}
$$

$$
\begin{aligned}
& \frac{\partial \rho}{\partial t}=-\underbrace{\lambda_{1} P \rho}_{\text {Degradation }}+\underbrace{\lambda_{2} \rho\left(1-\frac{\rho}{\rho_{*}}\right)}_{\text {Release/reconstruction }} \text { in } \Omega, \\
& \frac{\partial P}{\partial t}=\underbrace{D_{P} \Delta P}_{\text {Diffusion }}+\underbrace{\lambda_{3} \eta_{3}(x, P)}_{\text {Production by cells }}-\underbrace{\mu_{P} P}_{\text {Decay }} \text { in } \Omega,
\end{aligned}
$$

where $D_{G}, D_{C}, D_{P}$ are the diffusion coefficients of glucose, chemoattractant, and MMPs, respectively, $\lambda_{\text {in }}^{G}\left(\lambda_{\text {in }}^{G}\right)$ is the glucose (chemoattractant) injection rate on a subdomain $\Omega_{\epsilon}$ over time intervals $\left[t_{j}^{G}, t_{j}^{G}+\tau_{d}^{G}\right], j=1, \ldots, N_{G}\left(\left[t_{j}^{C}, t_{j}^{C}+\tau_{d}^{C}\right], j=1\right.$, $\left.\ldots, N_{C}\right)$ with a period $\tau^{G}\left(\tau^{C}\right)$ and duration $\tau_{d}^{G}\left(\tau_{d}^{C}\right)$ after the initial surgery at $t=t_{S}\left(t_{1}^{G}>t_{S}\right), \lambda_{b}$ is the glucose flux from a blood flow, $\lambda_{c}$ is the consumption rate of glucose by tumor cells, $\lambda_{1}$ is the degradation rate of ECM by MMPs, $\lambda_{2}$ is the release/reconstruction rate of ECM, $\lambda_{3}$ is the secretion rate of MMPs by tumor cells, $\mu_{G}$ is the glucose removal rate from the system via blood flow and glucose consumption in the surrounding tissue (Chiro et al., 1982; Rozental et al., 1991; Goldman et al., 1996; Aronen et al., 2000; Valle-Casuso et al., 2012), $\mu_{C}, \mu_{P}$ are decay rates of chemoattractant and MMPs, respectively. Here, indicator functions $\left(\eta_{1}, \eta_{2}, \eta_{3}\right)$ are given by

$$
\begin{aligned}
& \eta_{1}(x, G)=\left\{\begin{array}{ll}
1 & \text { blood vessel } \\
0 & \text { otherwise }
\end{array}, \quad \eta_{2}(x, G)=\left\{\begin{array}{ll}
1 & \text { tumor } \\
0 & \text { otherwise }
\end{array},\right.\right. \\
& \eta_{3}(x, P)= \begin{cases}1 & \text { invasive cells } \\
0 & \text { otherwise. }\end{cases}
\end{aligned}
$$

We also assume no flux (Neumann) boundary conditions $\frac{\partial G}{\partial v}=0, \frac{\partial C}{\partial v}=0, \frac{\partial P}{\partial v}=0$, on $\partial \Omega$. The reaction-diffusion equations (5-8) are solved on the regular grid using the alternatingdirection implicit (ADI) method and the non-linear solver $n k s o l$ for algebraic systems. A typical spatial grid size used is $h_{x}=h_{y}=0.01$ on a square domain $[0,1] \times[0,1]$. An adaptive time stepping method is used. Table 1 lists parameter values and references values for the equations (5)-(8).

\subsection{MATHEMATICAL MODELING OF miR-451-AMPK CONTROL}

The core control model of miR-451 activity and AMPK levels introduced in Kim et al. (2011a) was integrated into the hybrid model. Based on biological observations, we write the phenomenological equations for the rate change of those key molecules $(m$, a) as follows:

$$
\begin{aligned}
& \frac{d m}{d t}=\lambda_{g} g+\frac{\Lambda_{1} \Lambda_{2}^{2}}{\Lambda_{2}^{2}+\Lambda_{5} a^{2}}-\mu_{1} m, \\
& \frac{d a}{d t}=s+\frac{\Lambda_{3} \Lambda_{4}^{2}}{\Lambda_{4}^{2}+\Lambda_{6} m^{2}}-\mu_{2} a,
\end{aligned}
$$

where $g$ is the signaling pathways from glucose to miR-451, $s$ is the signaling pathways to AMPK complex, $\Lambda_{1}, \Lambda_{3}$ are the autocatalytic enhancement parameters for miR-451, AMPK complex, respectively, $\Lambda_{2}, \Lambda_{4}$ are the Hill-type inhibition saturation parameters from the counter part of miR-451 and AMPK complex, respectively, $\Lambda_{5}$ is the inhibition strength of miR-451 by the AMPK 
Table 1 | Values of reference variables and parameters used in the hybrid model.

\begin{tabular}{|c|c|c|c|}
\hline Var & Description & Value & Refs. \\
\hline \multicolumn{4}{|c|}{ DIFFUSION COEFFICIENTS } \\
\hline$D_{G}$ & Glucose & $6.7 \times 10^{-7} \mathrm{~cm}^{2} / \mathrm{s}$ & Jain (1987) \\
\hline$D_{P}$ & MMPs & $8.0 \times 10^{-9} \mathrm{~cm}^{2} / \mathrm{s}$ & Saffarian et al. (2004) \\
\hline \multicolumn{4}{|c|}{ PRODUCTION/DECAY/CONSUMPTION RATES } \\
\hline$\lambda_{c}$ & Glucose consumption rate by tumor & $0.8 \mathrm{pg} / \mathrm{cell} / \mathrm{min}$ & TW \\
\hline$\mu_{G}$ & Removal rate of glucose in brain tissue & $0.0034 \mathrm{~min}^{-1}$ & TW \\
\hline$\mu_{C}$ & Decay rate of chemoattractant (EGF) & $8.02 \times 10^{-6} \mathrm{~s}^{-1}$ & Kudlow et al. (1986) \\
\hline$\lambda_{1}$ & ECM degradation rate by MMPs & $3.0 \times 10^{4} \mathrm{~cm}^{3} \mathrm{~g}^{-1} \mathrm{~s}^{-1}$ & TW \\
\hline$\mu_{P}$ & Decay rate of MMPs & $5.0 \times 10^{-5} \mathrm{~s}^{-1}$ & TW \\
\hline$C^{*}$ & Chemoattractant (EGF) concentration & $1.0 \times 10^{-8} \mathrm{~g} / \mathrm{cm}^{3}$ & Boccardo et al. (2003), Sadlonova et al. (2005) \\
\hline$\rho^{*}$ & ECM concentration & $1.0 \times 10^{-3} \mathrm{~g} / \mathrm{cm}^{3}$ & Kaufman et al. (2005), Stein et al. (2007) \\
\hline$P^{*}$ & MMP concentration & $1.0 \times 10^{-7} \mathrm{~g} / \mathrm{cm}^{3}$ & Annabi et al. (2005) \\
\hline
\end{tabular}

complex, $\Lambda_{6}$ is the inhibition strength of the AMPK complex by $\mathrm{miR}-451, \mu_{1}, \mu_{2}$ are microRNA/protein degradation rates of miR451 and AMPK complex, respectively. Table A1 in Appendix summarizes the dimensionless parameters. By taking the thresholds $t h_{M}(=2.0)$ of miR-451 levels and $t h_{A}(=2.0)$ of AMPK complex, we shall define the migratory region $M_{m}$ by $M_{m}=\left\{(M, A) \in \mathbb{R}^{2}\right.$ : $\left.M<t h_{M}, A>t h_{A}\right\}$ and the proliferative region $M_{p}$ by $M_{p}=\{(M$, $\left.A) \in \mathbb{R}^{2}: M>t h_{M}, A<t h_{A}\right\}$. See Figure $2 \mathrm{C}$ for a diagram for proliferative and migratory regions.

\section{RESULTS}

In this Section, we present analysis of the hybrid model and predictions for therapeutic strategies for eliminating invasive glioma cells.

\subsection{DYNAMICS OF THE MODEL}

In order to validate the mathematical model, we first investigated invasion patterns of glioma cells embedded in high and low glucose levels in the absence of blood supply of glucose $\left(\lambda_{b}=0\right)$, glucose injection $\left(\lambda_{\text {in }}^{G}=0\right)$ and chemoattractants, and by assuming cells on the surface of the spheroid are migrating toward the glucose gradient $(\nabla G)$ [i.e., by replacing $\frac{\nabla C}{\sqrt{K_{C}+|\nabla C|}}$ with $\frac{\nabla G}{\sqrt{K_{G}+|\nabla G|}}$ in the active force form in the equation (3)]. Figures $\mathbf{3 A}-\mathrm{C}$ show spatial profiles of tumor spheroids in response to high $\left(G_{0}=1.0\right)$, intermediate $\left(G_{0}=0.5\right)$, and low $\left(G_{0}=0.1\right)$ glucose levels. Figure 3D shows relative miR-451 levels in response to high (Glucose +$)$ and low (Glucose-) levels in simulations and experiments (U251 and LN229 cell lines) (Godlewski et al., 2010a). General patterns of tumor spheroids in response to high (Figure 3A) and low (Figure 3C) glucose levels in simulations are in good agreement with experimental observations in Godlewski et al. (2010a) where high $(4.5 \mathrm{~g} / \mathrm{l})$ and low $(0.3 \mathrm{~g} / \mathrm{l})$ levels of glucose induced over- and under-expression of miR-451 (see Figure 3D), leading to proliferating (as in Figure 3A) and dispersed invasive (as in Figure 3C) patterns of tumor cells, respectively.

We investigate invasion dynamics of a growing tumor in response to glucose levels in the presence of blood supply. Figures $4 \mathrm{~A}-\mathrm{C}$ show spatial patterns of a growing/invading tumor in response to glucose supply $\left(G_{0}=10\right)$ at time $t=0,20,30 \mathrm{~h}$. Initial high glucose level is decreased due to glucose consumption by tumor cells at the center of the domain and nearby tissue (Figures 4D-F). The miR-451 activity at cell sites is decreased and AMPK levels creep up due to decreased glucose levels (Figures 4M,N). Cells on the surface of the tumor mass immediately respond to intracellular biochemical signals (miR451 and AMPK levels) and begin to migrate when miR-451 level drops below the threshold $\left(M<t h_{M}=2.0\right)$ and AMPK level is up-regulated $\left(A>t h_{A}=2.0\right)$ due to decreased glucose level at the cell site (cf. Figure $2 \mathrm{C}$ ). However, cells at the center of the tumor mass are surrounded by neighboring cells and stay inside the tumor due to physical constraints despite biochemical migration signals $\left(M<t h_{M}, A>t h_{A}\right)$. Figure $4 \mathrm{~N}$ shows time courses of miR-451 activities and AMPK levels in response to glucose levels in Figure $\mathbf{4 M}$ at two cell sites [cell id $=220$ with initial location (108.2, 99.5); cell id $=160$ with initial location (100.5, 99.8)]. The miR-451 levels for both cells drop below the threshold $\left(t h_{M}\right)$ and AMPK levels are above the threshold $\left(t h_{A}\right)$ around $t=16 \mathrm{~h}$ already, generating "migratory" signal. However, the cell (marked in "gray"; cell id=220) in Figure 4A still stays in the tumor mass at $t=20 \mathrm{~h}$ (Figure 4B) and begins to shed off at later time ( $t=26 \mathrm{~h}$; arrow in Figure $4 \mathrm{~N})$ when free space is available. Another cell (cell id $=160$ ) at the center of domain remains at the center of the tumor due to physical constraints until final time $[t=40 \mathrm{~h}$; final location $(100.3,99.7)]$. When glioma cells on the surface of the tumor mass migrate into surrounding brain tissue, proteinases (MMPs) are secreted in the invading front and ECM is degraded due to high levels of MMPs (proteolysis). See localized 

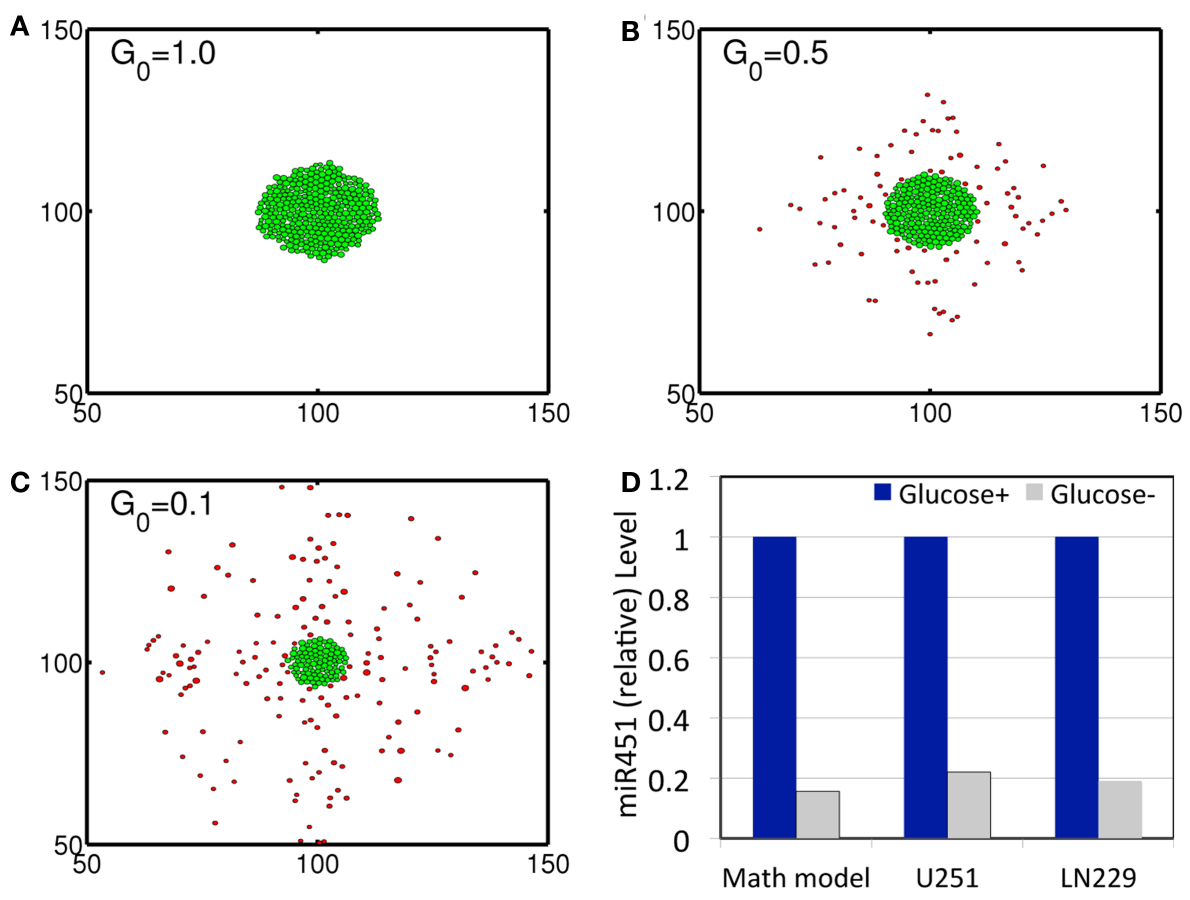

FIGURE 3 | (A-C) Profiles of tumor spheroid in response to high $(G=1.0)$, intermediate $(G=0.5)$, and low $(G=0.1)$ glucose levels at $t=30 \mathrm{~h}$. Domain size $=[50 \mu \mathrm{m}, 150 \mu \mathrm{m}] \times[50 \mu \mathrm{m}, 150 \mu \mathrm{m}]=[0.25,0.75]^{2}$ in the

dimensionless domain $[0,1]^{2}$ ). (D) Comparison between simulation results and experimental data. In response to high (Glucose+, blue) and low

MMPs at cell sites and degraded ECM profiles in Figures 4G-L, respectively.

Figures 5A-D show cyclic tumor growth patterns at $t=0,20$, $38,46 \mathrm{~h}$ in response to periodic glucose injection. When high doses $(G=10.0)$ of glucose are introduced into the system at $t=0,26 \mathrm{~h}$, fluctuating glucose values (Figure 5E) at a cell site (cell id $=220$; arrowhead in Figures 5A-D) lead to a cycle of up-regulation and down-regulation of miR-451 (Figure 5F). Cells outside the tumor core respond to this stimulus by either proliferating or migrating. See Figures 5A-D. Cell phenotype changes between proliferative and migratory cells are more clear in Figure 5G. Initial proliferative cells due to high glucose levels change their phenotype to become migratory cells whenever glucose level lowered to induce migratory phase $\left[M>t h_{M}, A<t h_{A} ; \sim t=16 \mathrm{~h}\right.$ (black arrow) and $t=42 \mathrm{~h}$ (red arrow)]. These migratory cells change their phenotypes to proliferative cells $(\sim t=26 \mathrm{~h}$; black arrowhead) when the high glucose level from glucose injection induces proliferative phase $\left(M>t h_{M}, A<t h_{A}\right)$.

\subsection{SENSITIVITY OF THE MODEL TO INHIBITION PARAMETERS $(\alpha, \beta)$ IN THE CORE SYSTEM}

From now on, the activation time for invasion is defined to be time when a cell in proliferative phase $\left(M>t h_{M}, A<t h_{A}\right)$ changes its phenotype to a migratory cell $\left(M<t h_{M}, A>t h_{A}\right)$ due to a microenvironmental change (glucose fluctuation) and begins to migrate away from the main tumor aggregate for the first time among all other cells. In Figure 6A we show steady state values

(Glucose-, gray) glucose levels, miR-451 expression levels are quantified. Simulation results are in good agreement with experimental results on U251 and LN229 cell line in Godlewski et al. (2010a). ${ }^{*} \lambda_{b}=0, \lambda_{\text {in }}^{G}=0$. It was assumed that tumor cells respond to the glucose gradient for migration in vitro as in Godlewski et al. (2010a). of miR-451 $\left(M^{s}\right)$ in response to different glucose levels for various inhibition strength $(\beta)$ of AMPK complex by miR-451. See Appendix A. 2 for definition and role of $\beta$ (and $\alpha$ below) in the core system. As $\beta$ is decreased the bifurcation curve shifts to the right (higher glucose levels). In the control case $(\beta=1.0)$, a relatively low glucose level $(G=0.4)$ is required for activation of cell invasion. When this inhibition strength is weakened ( $\beta$ small), a cell may begin to migrate for larger glucose levels. Figure 6B shows activation time for invasion as a function of inhibition strength of AMPK complex production $(\beta)$. As $\beta$ is decreased from control base parameter $(\beta=1.0)$, the rate of AMPK complex formation is increased and miR-451 level is decreased at earlier time, leading to early activation time for invasion. This might have biological implications. For example, one could totally use or partially block inhibition pathways from miR-451 to AMPK (decrease in $\beta$ ) in order to boost invasion activation under certain circumstances.

Figures 7A,B show effect of inhibition strength $(\alpha)$ of miR-451 production by AMPK complex on tumor population and activation time for cell invasion. As the inhibition strength $\alpha$ is increased, miR-451 levels are decreased at earlier time (Figure 7B) and more cells on the surface of the tumor mass migrate from the biochemical signal. See Figure 7A. This would have several implications. For example, cell migration or dispersion might be prevented by any drug that blocks inhibitory activity of AMPK complex to miR451. This may generate faster growth of tumor mass since most of cells would be in proliferative phase. Therefore, this could be used 

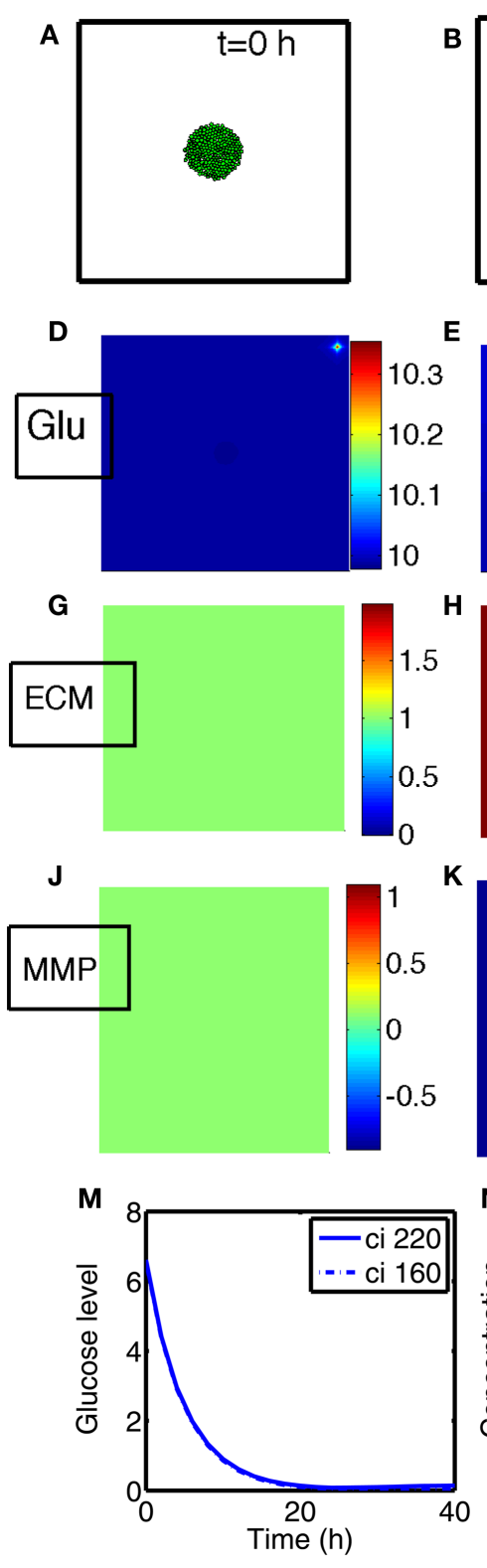

FIGURE 4 | (A-C) Tumor invasion pattern at time $t=0,20,30 \mathrm{~h}$ in response to glucose levels $\left(G_{0}=10\right)$. Domain size $=[0.25,0.75] \subset[0,1]^{2}$. (D-F) Profiles of glucose concentration on the domain $[0,1] \times[0,1]$. Glucose flux from a blood vessel induces a peak value at the upper right corner. (G-I) Profiles of ECM on the subdomain $[0.25,0.75] \times[0.25$,
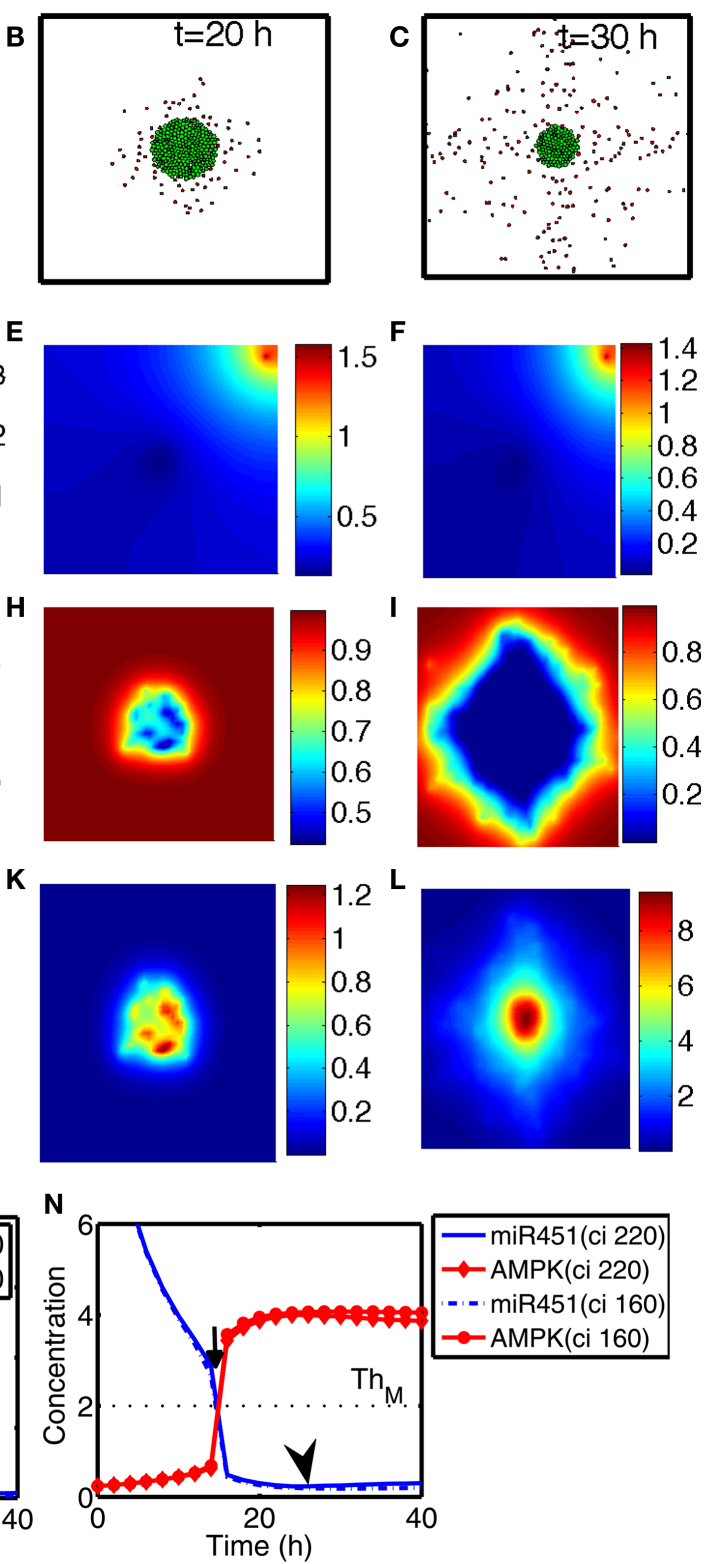

as a temporary way of holding cell migration in order to not miss out single migratory cells for surgery.

\subsection{PREDICTIONS OF THE MODEL FOR A POSSIBLE THERAPEUTIC APPROACH}

In this section, we developed therapeutic strategies for eradicating invisible migratory glioma cells in the brain after conventional surgery where only visible parts of tumor mass are removed. Here we assume that invasive cells in surrounding tissue can sense and respond to the chemoattractant gradient $(\nabla C)$.
$0.75] \subset[0,1]^{2}$. ECM were degraded in the invasive region. (J-L) Profiles of MMPs on the subdomain $[0.25,0.75] \times[0.25,0.75] \subset[0,1]^{2}$. MMPs are localized in tumor region. (M) Glucose levels at two cell sites (cell id $=220$, 160). (N) Concentrations of intracellular variables, miR-451 and AMPK complex, at the cell sites in (M). 

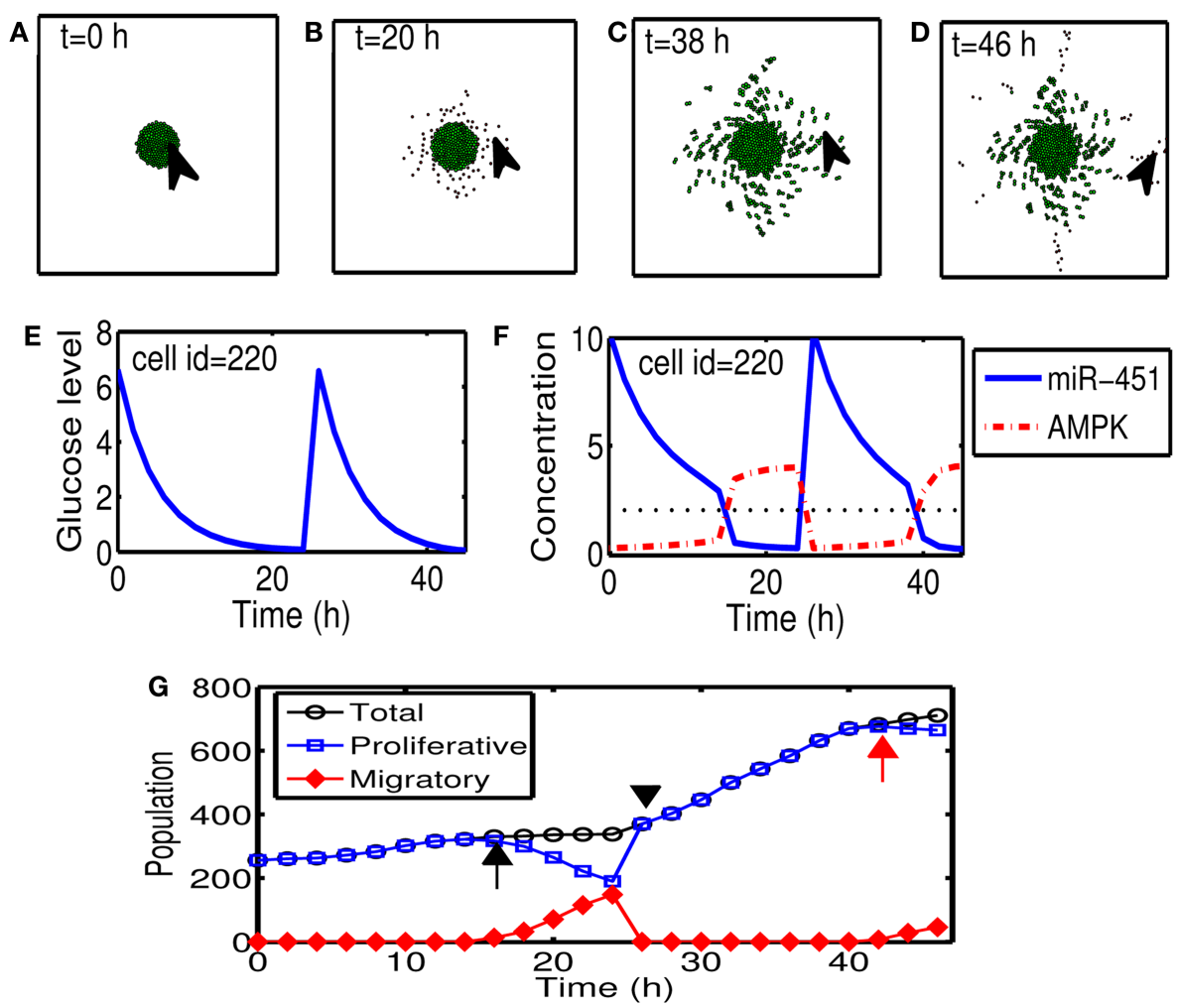

FIGURE 5 | (A-D) Tumor growth patterns at $t=0,20,38,46 \mathrm{~h}$ in response to glucose injection. Two cycles of proliferation-migration pattern are observed after initial $(t=0 \mathrm{~h})$ and second $(t=26 \mathrm{~h})$ injections of glucose $(G=10)$. Domain size $=[0.2,0.8] \times[0.2,0.8] \subset[0,1]^{2}$. (E) Glucose level at a cell site [cell id =220; arrowhead in (A-D)]. (F) Time course of miR-451 activity and AMPK concentration at the cell site in (E). Dotted black line in the middle $=$ threshold value of miR-451 $\left(t h_{M}\right) .(\mathbf{G})$ Time course of cell populations: proliferative (blue square), migratory (red diamond), and total (black circle) cells. Some of proliferative cells become migratory ones around $t=16 \mathrm{~h}$ (black arrow) and $t=42 \mathrm{~h}$ (red arrow) when miR-451 levels drop below threshold due to lowered glucose levels. All migratory cells enter the proliferative phase around $t=26$ (black arrowhead) in response to glucose injection.

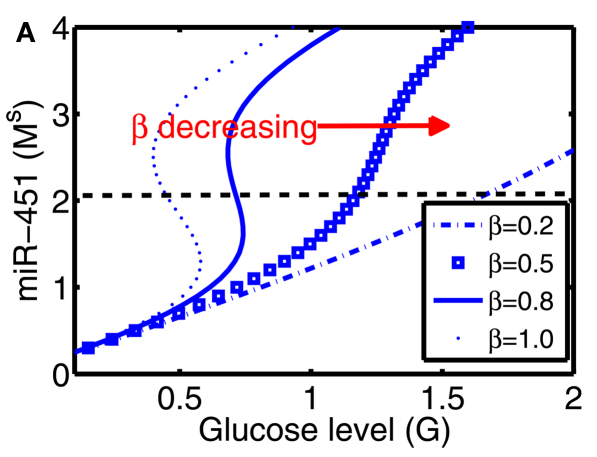

FIGURE 6 | (A) Steady state values of miR-451 $\left(M^{s}\right)$ as a function of glucose level $(G)$ for various inhibition strength of AMPK by miR-451 $(\beta)$ in core control system. (B) Effect of the inhibition rate $(\beta)$ on activation time

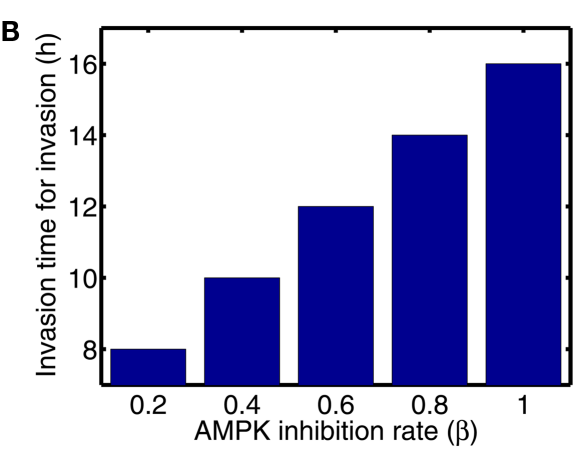

for glioma cell invasion in the hybrid model. As $\beta$ is decreased, activation time for invasion is decreased. See Appendix A.2 for definition and role of $\beta$ in the core system.

cells outside the blue circle are still migratory cells in migratory phase $\left(M<t h_{M}, A>t h_{A}\right)$ from low glucose levels. While infiltrative tumor cells after surgery may not be detected, regrown tumor mass may be detected by conventional screening tools such as MRI when tumor density is high enough. This may increase the probability of eliminating invasive cells. 

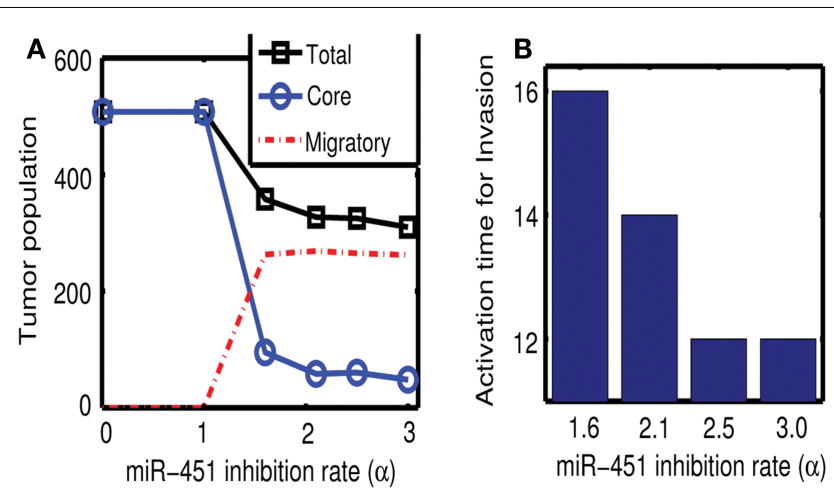

FIGURE 7 | (A) Effect of miR-451 inhibition strength $(\alpha)$ on tumor population. As $\alpha$ is increased, miR-451 production rate is decreased leading to low miR-451 activity and activation of glioma cell migration. (B) Effect of $\alpha$ on activation time for cell invasion. As $\alpha$ is increased, lowered miR-451 activity leads to early activation of cell invasion. See Appendix A.2 for definition and role of $\alpha$ in the core system.

Figure 10 shows time courses of average cell speeds of migratory (solid circle, red) and proliferative (blue square) cells in Figure 8. From the beginning of the simulation, the average cell speed of cells in migratory phase maintained the values in the rage of $27-33 \mu \mathrm{m} / \mathrm{h}$ until cell speeds begin to drop down around $\sim 17 \mathrm{~h}$ due to cell aggregation at the center of domain. Eventually all migratory cells become proliferative cells around $t=19$ h. Proliferative cells (blue square, transformed from migratory cells around $9 \mathrm{~h}$ ) show very low cell speeds due to absence of active force since their movement is due to growth not cell movement. Cell speeds have been reported to be in the range of $39-45 \mu \mathrm{m} / \mathrm{h}$ in $2 \mathrm{D}$ barrier-free culture condition and 15$20 \mu \mathrm{m} / \mathrm{h}$ in $3 \mathrm{D}$ glioblastoma cell culture in the absence/presence of EGF-stimulation (Kim et al., 2008), 15-25 $\mu \mathrm{m} / \mathrm{h}$ in glioblastoma cells with/without $\alpha$-actinin isoforms (Sen et al., 2009), $15-48 \mu \mathrm{m} / \mathrm{h}$ for cells embedded in collagen I matrix (Kaufman et al., 2005). So, the cell speed in our model is in good agreement with experimental data.

To test our hypothesis in a more realistic situation, we tested our hypothesis of attracting cancer cells back to the resection bed in a more realistic setting in Figure 11. Here we assume that a cell can sense the environment of the resection bed and stop moving on the edge of the resection bed. In our simulation, generation of active force of a migratory cell is turned off, i.e., active force $\mathbf{T}_{\mathrm{i}}$ in the equation ( 3 ) is set to be zero when the cell reaches periphery of the resection bed. The simulation begins immediately after initial surgery of the large tumor mass at the center of the domain again. Figures $\mathbf{1 1} \mathbf{A}-\mathbf{H}$ show proliferation and migration patterns of tumor cells at $t=0,8,16,24,32,40,48,56 \mathrm{~h}$ in response to initial injection of a chemoattractant $(t=0 \mathrm{~h})$ followed by glucose injection at $t=17 \mathrm{~h}$. Figures 11I,J show time courses of miR-451 activity and AMPK level at a cell site (cell id=22) and cell populations [proliferative (blue circle), migratory (red dotted), and total (green square) cells], respectively. Initially, there exist only a phenotype of migratory cells but these cells begin to aggregate on the periphery of the resection bed. However, these cells switch their phenotype to proliferative ones via core control system (Figure 11I) in response to glucose injection at $t=17 \mathrm{~h}$. These proliferative cells form a visible larger tumor mass which can be ready for the second follow-up surgery. Most of these proliferative cells enter the migratory phase $\left(M<t h_{M}, A>t h_{A}\right)$ again around $t=49 \mathrm{~h}$ due to lowered glucose levels.

\subsection{THERAPEUTIC OPTIMIZATION}

In Figures 12A-F, we investigate the effect of glucose injection time on tumor growth patterns for chemoattractant-induced second surgery under same conditions as in Figure 8. Figures 12A-D illustrate spatial growth patterns of tumor cells at final time $(t=44 \mathrm{~h})$ when a high dose of glucose was injected at the center of the surgical site at different initial injection time $\left(t_{1}^{G}=\right.$ $10,12,15,17 \mathrm{~h})$. When glucose was injected at the earlier time $\left(t_{1}^{G}=10 \mathrm{~h}\right)$, more invasive cells enter the cell cycle $\left(M>t h_{M}\right.$, $A<t h_{A}$ ) for higher flux of glucose before they reach the surgical site. For the case of glucose injection at later time $\left(t_{1}^{G}=17 \mathrm{~h}\right)$, more cells are localized at the center of the surgical site. Figure 12E shows tumor population at final time. Cells inside the bigger size of tumor mass are subject to slower growth (see mechanical aspects of the hybrid model). Initial glucose injection time decreases tumor population since more tumor cells are activated for proliferation and tumor cells grow faster without physical constraints. This injection time also decreases resection area for second surgery due to localized tumor cells at the original surgical site (Figure 12F). Therefore, choosing appropriate injection time is important for efficacy of tumor treatment. However, any further delay of second surgery would lead to larger size of tumor mass and one may face another possibility of tumor invasion.

Next, we investigate the effect of chemoattractant strength on efficacy of therapeutic strategies suggested in this paper. Figures $13 \mathrm{~A}-\mathrm{F}$ show migration-proliferation patterns of tumor cells at $t=0,17,56 \mathrm{~h}$ in the presence of low $\left(\bar{\lambda}_{\text {in }}^{C}=\lambda_{\text {in }}^{C / 10}\right)$ and high (control) levels of a chemoattractant and glucose injection at $t=17 \mathrm{~h}$ after initial surgery at $t=0 \mathrm{~h}$. When the chemoattractant level is low, cells in the far away field do not effectively respond to the chemotactic signals (red arrows in Figure 13B) and do not move toward the resection bed easily, which induces further tumor growth later at the undesirable location (black arrowheads in Figure 13C). Figures 13G,H show populations of localized cells (cells with $d<0.25$ ) and cells outside the localized domain (cells with $d>0.25)$, respectively. Here, $d=\sqrt{\left(x_{i}-0.5\right)^{2}+\left(y_{i}-0.5\right)^{2}}$ is the distance from cell location $\left(x_{i}, y_{i}\right)$ to the center $(0.5,0.5)$ of the domain. One can see that the low chemoattractant level leads to a moderate decrease in the population of localized cells (Figure 13G) but induces a significant increase in the population of cells in the far away field (Figure 13H) at $t=17,56 \mathrm{~h}$. These missed cells reduce efficacy of second surgery. These results effectively show that enough levels of chemoattractant need to be provided for the more efficient therapy.

\section{DISCUSSION}

One major challenge for treating glioblastoma is that by the time the disease is diagnosed cancer cells have already invaded other parts of the brain, inhibiting complete elimination of cancer cells. Blocking this critical invasion process or finding a 

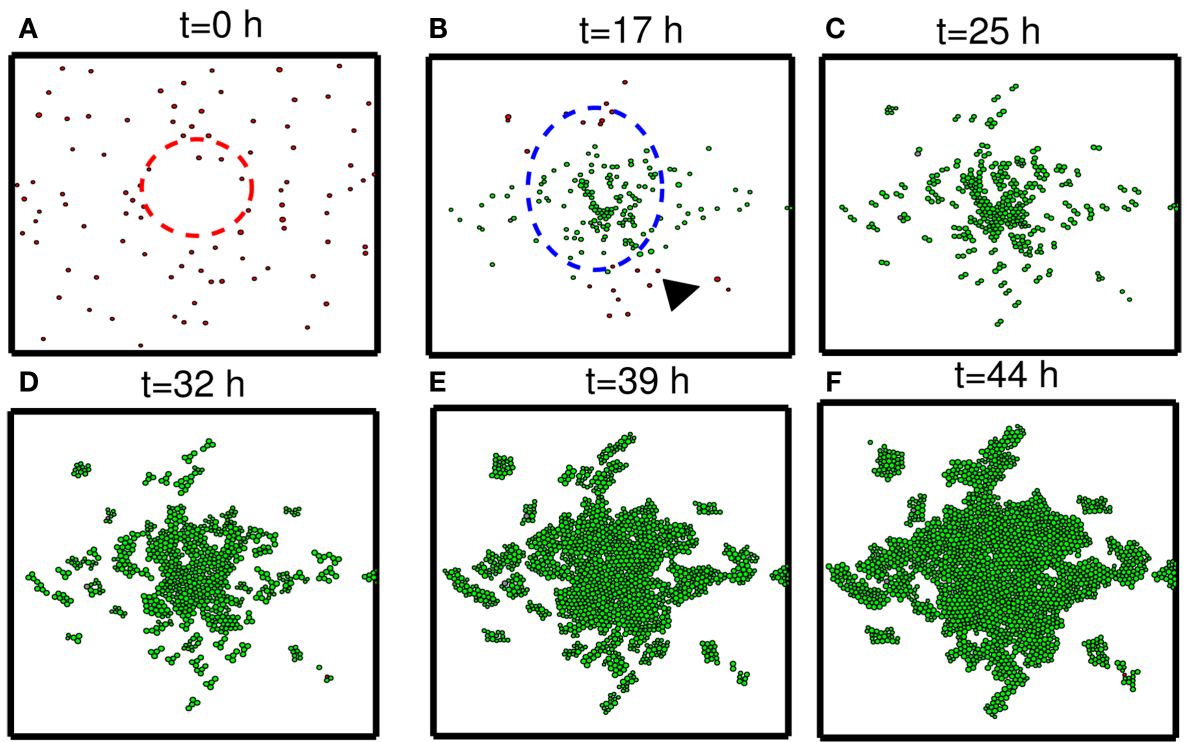

FIGURE 8 | Strategy of eradicating migratory cells after first surgery. (A-F) Spatial profile of a surgically removed tumor at $t=0,17,25,32,39$, $44 \mathrm{~h}$. Detectable tumor core was surgically removed at $t=0 \mathrm{~h}$ (red dotted circle) and a chemoattractant was injected at the center of the removed area immediately after surgery $(t=0 \mathrm{~h}$ ). After waiting $17 \mathrm{~h}$, glucose was injected at the center of the removed area again in order to turn the migratory switch $\left(M<t h_{M}, A>t h_{A}\right)$ off and make these cells grow $\left(M>t h_{M}, A<t h_{A}\right)$. This growing mass of tumor may be visible for secondary surgery, leading to eradication of invisible migratory cells. Domain size $=[0.25,0.75] \times[0.25$, $0.75] \subset[0,1]^{2}$

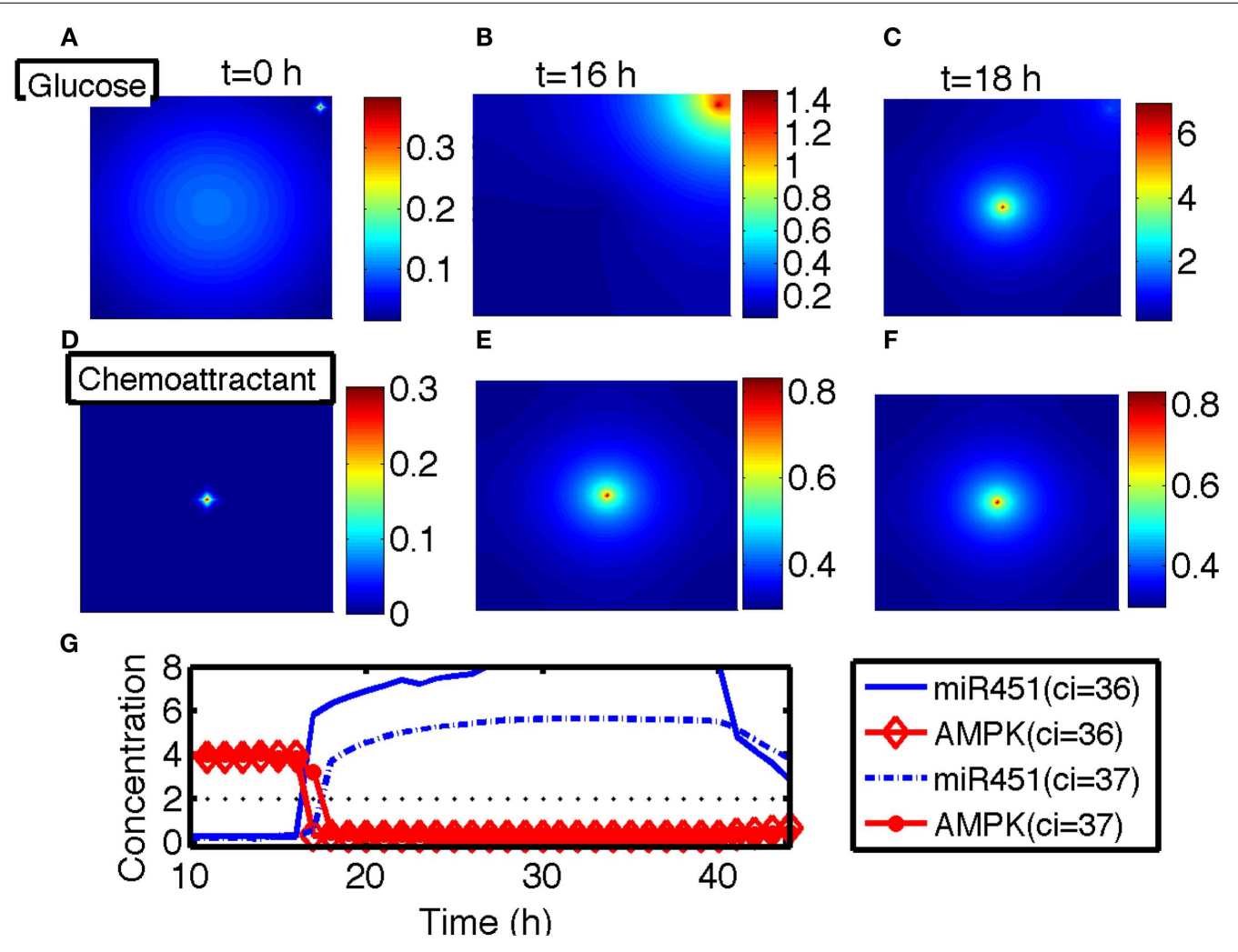

FIGURE 9 | (A-C) Spatial profiles of glucose at $t=0,16,18 \mathrm{~h}$. Glucose was injected at the center of the domain around $t=17 \mathrm{~h}$. Glucose flux from a blood vessel induces a peak value at the upper right corner. (D-F) Spatial profiles of chemoattractant at $t=0,16,18 \mathrm{~h}$. Chemotactic source was located at the center of the domain. (G) Time course of the miR-451 activity and AMPK level at two cell sites (cell id $=36,37$ ). ${ }^{*}$ Domain size in $(\mathbf{A}-\mathbf{F})=[0,1]^{2}$. 
way of eradicating invasive tumor cells would lead to better clinical outcomes. Godlewski et al. (2010a) recently identified a key miRNA, miR-451, and its target, AMPK complex, that

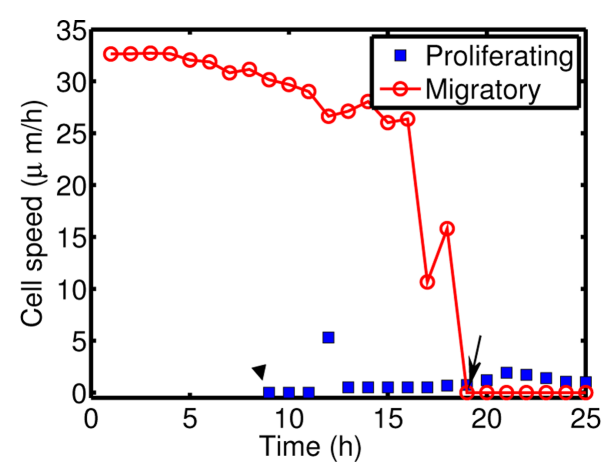

FIGURE 10 | Cell speeds of proliferative (blue square) and migratory (solid circle, red) cells in Figure 8. regulates a critical switch between cell migration and proliferation. Reduced miR-451 activity has been associated with cancers (Bandres et al., 2009) including glioma (Gal et al., 2008; Godlewski et al., 2010a). In the harsh microenvironment, glioblastoma cells shift their metabolic machinery toward a high level of glucose uptake, Warburg effect (Warburg, 1956; Kim and Dang, 2006; Heiden et al., 2009), and lowered glucose levels trigger active cell migration toward the better microenvironment. Some upregulated miRNAs in brain tumors are believed to play a prooncogenic role via supporting growth, proliferation, migration, and survival of cancer cells while expression of other miRNA having anti-tumor effects is suppressed in gliomas. These miRNAs harbor a therapeutic significance as therapeutic agents in anti-cancer therapy (Lawler and Chiocca, 2009; Godlewski et al., 2010b; Chistiakov and Chekhonin, 2012). Godlewski et al. (2010a) illustrated glucose regulation of proliferation and migration of glioma cells: (i) low glucose $\Rightarrow$ down-regulation of miR-451 and up-regulation of the AMPK complex $\Rightarrow$ cell migration (ii) normal (high) glucose $\Rightarrow$ up-regulation of miR-451 and down-regulation of AMPK complex $\Rightarrow$ proliferation.

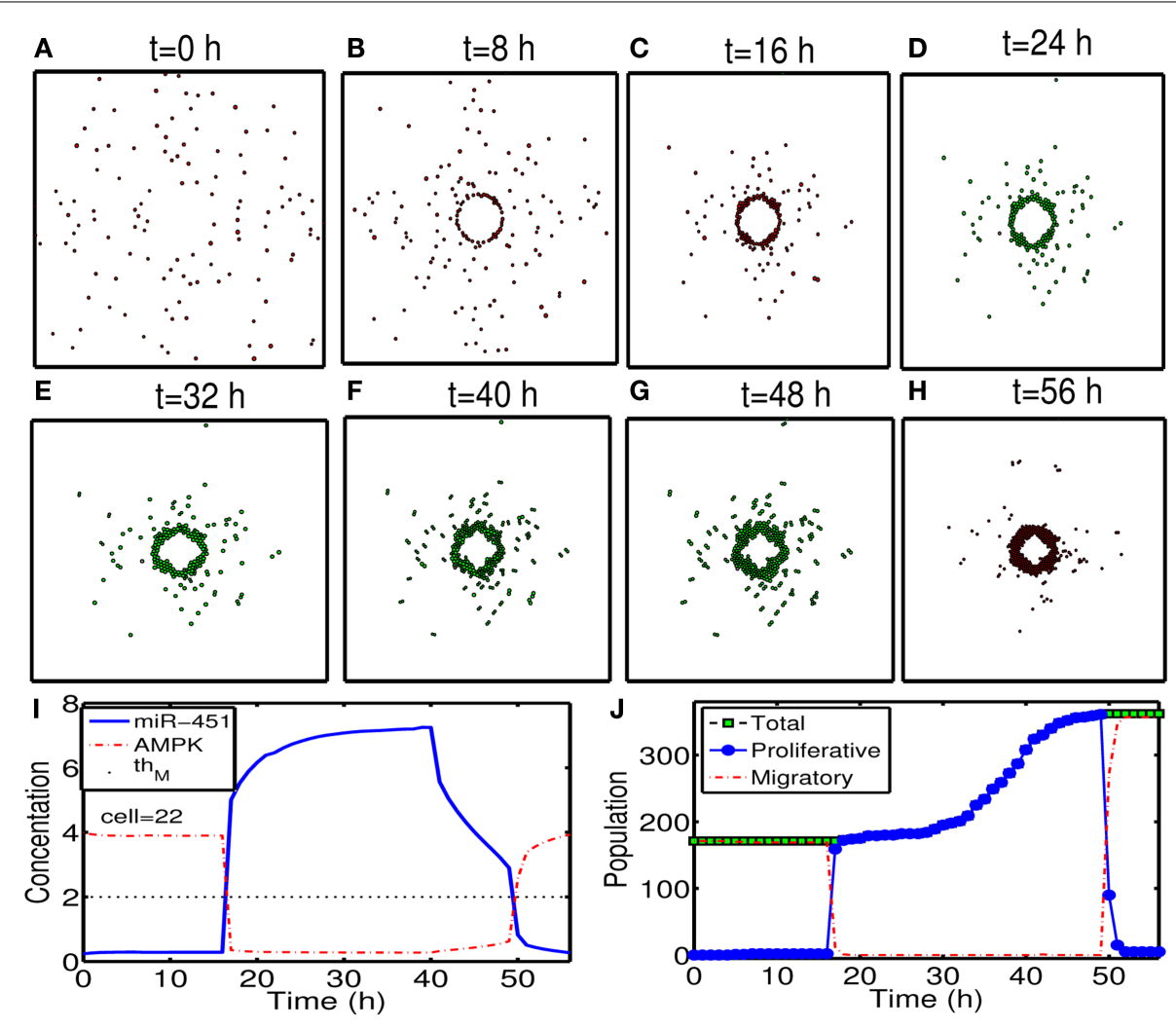

FIGURE 11 | (A-H) Tumor migration-proliferation patterns at $t=0,8,16$, $24,32,40,48,56 \mathrm{~h}$ in response to injection of a chemoattractant at $t=0 \mathrm{~h}$ and glucose at $t=17 \mathrm{~h}$ after initial surgery at $t=0 \mathrm{~h}$. Migratory cells switch to proliferative phenotype, forming a visible larger tumor mass, in response to glucose for second follow-up surgery. Migratory cells stop on the periphery of the resected area from the first surgery. It was assumed that a cell can sense the environment of the resection bed and the active force of a migratory cell is set to be zero when the cell reaches the periphery of the resection bed. Domain size $=[0.2,0.8] \times[0.2,0.8] \subset[0$,
1] ${ }^{2}$. (I) Time course of miR-451 activity and AMPK level at a cell site (cell $i d=22)$. Dotted black line in the middle =threshold value of miR-451 $\left(t h_{M}=2.0\right)$. (J) Time course of cell populations: proliferative (blue circle), migratory (red dotted), and total (green square) cells. All migratory cells switch to proliferative ones around $t=17 \mathrm{~h}$ when low miR-451 levels jump to higher value $[M>5$ in (I)] and the level stays above threshold (thM $=2.0$ ) due to glucose injection. Most of these proliferative cells enter the migratory phase $\left(M<t h_{M} A>t h_{A}\right)$ again around $t=49 \mathrm{~h}$ due to lowered glucose levels. Parameters used: $t_{1}^{G}=17 \mathrm{~h}, \tau_{d}^{G}=24 \mathrm{~h}$. 

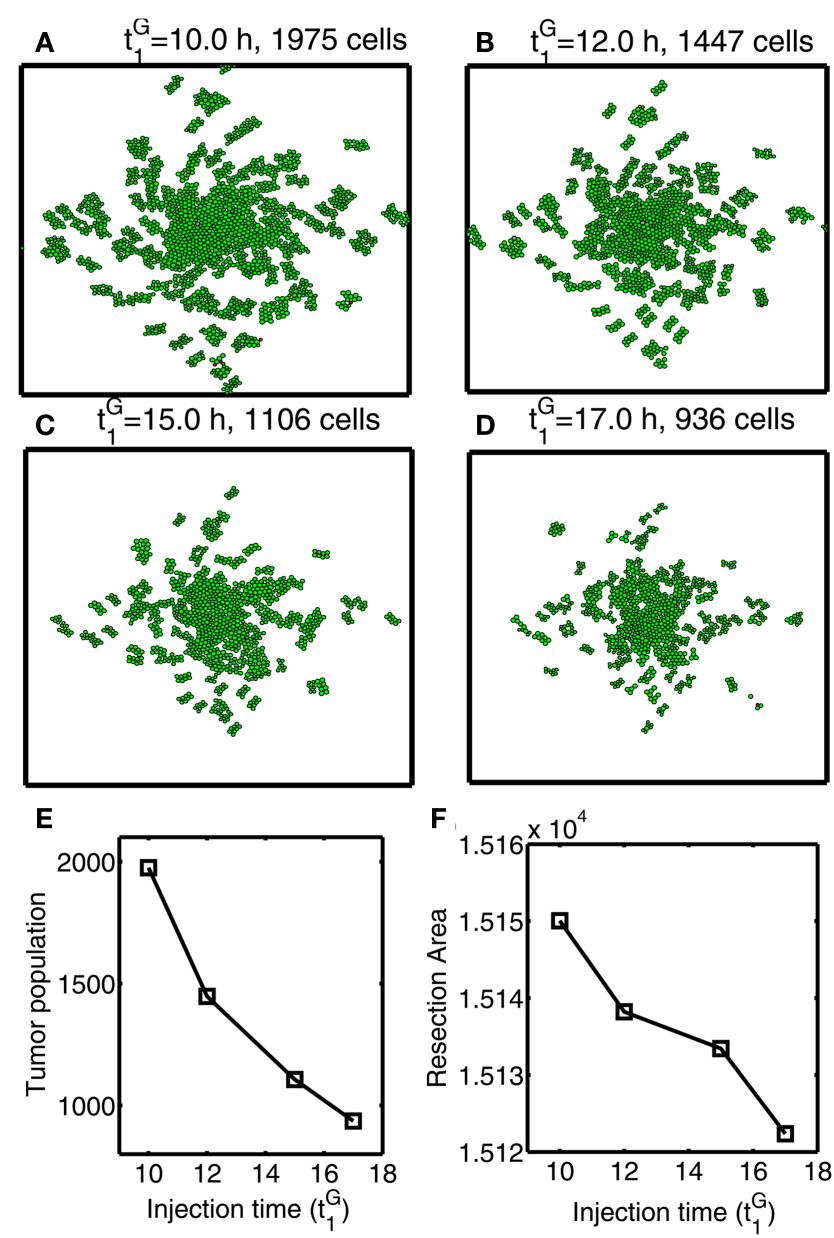

FIGURE 12 | Optimal strategy for glucose injection for second surgery after attracting invasive cells via chemotaxis. (A-D) Growth patterns at final time $(t=33 \mathrm{~h})$ for various glucose injection time $\left(t_{1}^{G}=10(A), 12(B), 15(C), 17 h(D)\right)$. Domain size $=[0.2,0.8] \times[0.2$,

Conventional treatment options such as radiotherapy and chemo therapy after surgical resection of tumor mass lead to poor clinical outcome in many cases of glioblastoma due to invisible migratory cancer cells in the brain tissue. In the present paper we aimed at understanding a basic mechanism of proliferation and migration of glioma cells in response to fluctuating glucose levels and developing therapeutic strategies for eradicating invasive glioma cells after initial conventional surgery. The present paper develops a hybrid mathematical model of glioma cell migration and proliferation. The hybrid model considers proliferation and migration of individual tumor cells based on cell-mechanics, concentrations of glucose, chemoattractant, ECM, and MMPs in a spatio-temporal domain, and regulation of key intracellular molecules, miR-451 and AMPK complex, at each cell site. Mechanical stress and active forces acting on tumor cells were taken into account in the model. The spatial distribution of both proliferative and migratory cells in response to high and low glucose levels is in good agreement with experiments (Godlewski et al., 2010a).
We first considered the important role that the core control system (miR-451, AMPK) plays in regulation of the migratory phase and proliferative phase when cells on the surface of tumor mass begin to migrate away from the main core in the harsh microenvironment where glucose levels fluctuate. We analyzed the migratory behavior of cells in response to variations in two key parameters, inhibition strength of miR-451 $(\alpha)$ and inhibition strength of AMPK complex $(\beta)$, that play a critical role in characterizing the invasion of glioma cells. Active migration of a cell depends on chemical signals from the core miR-451-AMPK system and their physical microenvironment in response to glucose injection. Growing tumor cells in the presence of abundant glucose switch their mechanism for cell migration when glucose is not available and cells are not subject to physical constraints. When glucose was introduced into the system in a periodic fashion, tumor repeat migration-proliferation cycle, which may lead to faster growth (Kim et al., 2011a).

For therapeutic strategies, the model suggested that (i) Introduction of chemoattractant at the surgical site may bring these 


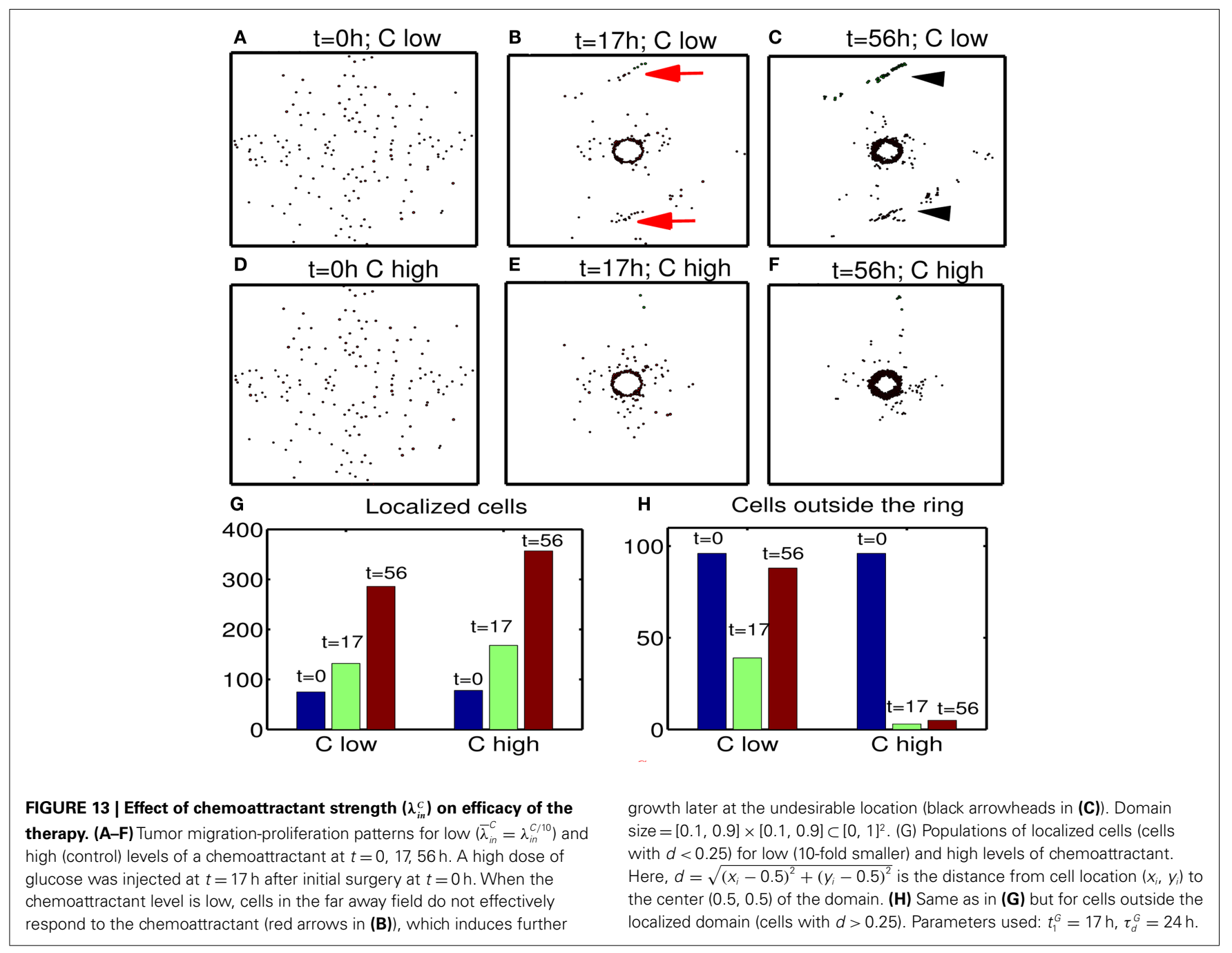

invasive tumor cells back to the tumor site. (ii) Glucose injection at the center of the surgical site would lead to up-regulation of miR-451 and down-regulation of AMPK complex, which induces cell proliferation. (iii) Follow-up surgery may eradicate the tumor cells that managed to survive from the first surgery. Multiple microsurgical resections for glioblastoma have been proven to be effective and useful (Hong et al., 2012). However, we also found that glucose injection at the wrong time may grow the tumor even before tumor cells gather together and this may lead to undesirable results, faster growth of dispersed tumor mass. Detecting appropriate time glucose injection and second surgery might also be a challenge. Tumor cells can be cultured from biopsies up to $4 \mathrm{~cm}$ away from the bulk tumor (Silbergeld and Chicoine, 1997). When cancer cells migrate too far from the original site, it may be difficult to attract these cells. For example, we found that too low chemoattractant may not be able to attract all migratory cells for second surgery (Figure 12) and these missed cells would decrease efficacy of the therapy. Therefore, in order to attract those invasive cells in the far away field ( $>4 \mathrm{~cm}$ away) one might need strong chemoattractants at the resection bed. However, this new strategy in this paper may be a novel way of eliminating all cancer cells when an appropriate combination of chemoattractants and glucose is used.

The analysis and predictions of the hybrid model in this paper may serve as a starting point for experimentation and more detailed modeling. We indicate several aspects and directions for further development of in vivo and/or in vitro multi-scale models: (i) One might use a multi-phase approach to describe the inhomogeneity of the microenvironment (Byrne and Preziosi, 2004; Preziosi and Tosin, 2009; Preziosi and Vitale, 2011). See a review (Lowengrub et al., 2010) for further discussion. (ii) It has been suggested that some glioma cells may migrate while they grow. We could incorporate this aspect easily in this hybrid framework. Collective cell migration is also considered as a key aspect of tumor invasion (Friedl and Alexander, 2011). Creating a microtrack of locally digested ECM followed by generating a larger excavated macrotrack by proteolysis was suggested as a way of collective cell migration (Wolf et al., 2007; Friedl and Alexander, 2011; Ilina et al., 2011). In recent study, Sampetrean et al. (2011) also illustrated the importance of collective migration along fiber tracts in glioma cell invasion, suggesting the need for anti-invasion approach. (iii) The simplified network of miR-451 and AMPK 
complex can be extended to the more detailed network in order to take into account cell cycle and other anti-cancer molecules. (iv) Some important players such as immune cells and cytokines in the microenvironment should be included in the model (Cheng and Weiner, 2003; Rejniak and McCawley, 2010; Wiranowska and Rojiani, 2011). (v) It was observed that isoforms of myosin II are specifically required for an adaptation needed to squeeze through the dense network of other cells (Beadle et al., 2008). Detailed

\section{REFERENCES}

Aguda, B. D., Kim, Y., Hunter, M. G., Friedman, A., and Marsh, C. B. (2008). MicroRNA regulation of a cancer network: consequences of the feedback loops involving miR-17-92, E2F, and Myc. Proc. Natl. Acad. Sci. U.S.A. 105, 19678-19683.

Annabi, B., Bouzeghrane, M., Currie, J. C., Hawkins, R., Dulude, H., Daigneault, L., et al. (2005). A PSP94-derived peptide PCK3145 inhibits MMP-9 secretion and triggers CD44 cell surface shedding: implication in tumor metastasis. Clin. Exp. Metastasis 22, 429-439.

Aronen, H. J., Pardo, F. S., Kennedy, D. N., Belliveau, J. W., Packard, S. D., Hsu, D. W., et al. (2000). High microvascular blood volume is associated with high glucose uptake and tumor angiogenesis in human gliomas. Clin. Cancer Res. 6, 2189-2200.

Bandres, E., Bitarte, N., Arias, F., Agorreta, J., Fortes, P., Agirre, X., et al. (2009). MicroRNA451 regulates macrophage migration inhibitory factor production and proliferation of gastrointestinal cancer cells. Clin. Cancer Res. 15 2281-2290.

Bartel, D. P. (2009). MicroRNAs: target recognition and regulatory functions. Cell 136, 215-233.

Beadle, C., Assanah, M. C., Monzo, P., Vallee, R., Rosenfield, S. S., and Canoll, P. (2008). The role of myosin II in glioma invasion of the brain. Mol. Biol. Cell 19, 3357-3368.

Boccardo, F., Lunardi, G. L., Petti, A. R., and Rubagotti, A. (2003). Enterolactone in breast cyst fluid: correlation with EGF and breast cancer risk. Breast Cancer Res. Treat. 79, 17-23.

Byrne, H., and Preziosi, L. (2004). Modeling solid tumor growth using the theory of mixtures. Math. Med. Biol. $20,341-360$

Chauviere, A., Preziosi, L., and Byrne, H. (2010). A model of cell migration within the extracellular matrix based on a phenotypic switching mechanism. Math. Med. Biol. 27, 255-281.

Cheng, J. D., and Weiner, L. M. (2003). Tumors and their microenvironments: tilling the soil commentary re: A. M. Scott et al., a phase I dose-escalation study of sibrotuzumab in patients with advanced or metastatic fibroblast activation protein-positive cancer. Clin. Cancer Res. 9, 1590-1595.

Chintala, S. K., Tonn, J. C., and Rao, J. S. (1999). Matrix metalloproteinases and their biological function in human gliomas. Int. J. Dev. Neurosci. 17, 495-502.

Chiro, D. G., DeLaPaz, R. L., Brooks, R. A., Sokoloff, L., Kornblith, P. L., Smith, B. H., et al. (1982). Glucose utilization of cerebral gliomas measured by [18f] fluorodeoxyglucose and positron emission tomography. Neurology 32, 1323-1329.

Chistiakov, D. A., and Chekhonin, V. P. (2012). Contribution of microRNAs to radio and chemoresistance of brain tumors and their therapeutic potential. Eur. J. Pharmacol. 684, 8-18.

Choe, G., Park, J. K., Jouben-Steele, L., Kremen, T. J., Liau, L. M., Vinters, H. V., et al. (2002). Active matrix metalloproteinase 9 expression is associated with primary glioblastoma subtype. Clin. Cancer Res. 8, 2894-2901.

Crute, B. E., Seefeld, K., Gamble, J., Kemp, B. E., and Witters, L. A. (1998). Functional domains of the alphal catalytic subunit of the ampactivated protein kinase. J. Biol. Chem. 273, 35347-35354.

Dallon, J. C., and Othmer, H. G. (2004). How cellular movement determines the collective force generated by the Dictyostelium discoideum slug. J. Theor. Biol. 231, 203-222.

Davis, F. G., and McCarthy, B. J. (2001). Current epidemiological trends and surveillance issues in brain tumors. Expert Rev. Anticancer Ther. 1, 395-401.

modeling work is necessary to take into account deformation of cell body for cell motility. We hope to address these issues in future work.

\section{ACKNOWLEDGMENTS}

This work was supported by the Basic Science Research Program through the National Research Foundation of Korea by the Ministry of Education and Technology (2012R1A1A1043340).

Deisboeck, T. S., Berens, M. E., Kansal, A. R., Torquato, S., StemmerRachamimov, A. O., and Chiocca, E. A. (2001). Pattern of selforganization in tumour systems: complex growth dynamics in a novel brain tumour spheroid model. Cell Prolif. 34, 115-134.

Demuth, T., and Berens, M. E. (2004). Molecular mechanisms of glioma cell migration and invasion. $\mathrm{J}$. Neurooncol. 70, 217-228.

Esquela-Kerscher, A., and Slack, F. J. (2006). Oncomirs - microRNAs with a role in cancer. Nat. Rev. Cancer 6, 259-269.

Friedl, P., and Alexander, S. (2011). Cancer invasion and the microenvironment: plasticity and reciprocity. Cell 147, 992-1009.

Gabriely, G., Wurdinger, T., Kesari, S. Esau, C. C., Burchard, J., Linsley, P. S., et al. (2008). MicroRNA 21 promotes glioma invasion by targeting matrix metalloproteinase regulators. Mol. Cell. Biol. 28, 5369-5380.

Gal, H., Pandi, G., Kanner, A. A., Ram, Z., Lithwick-Yanai, G., Amariglio, N., et al. (2008). Mir-451 and imatinib mesylate inhibit tumor growth of glioblastoma stem cells. Biochem. Biophys. Res. Commun. 376, 86-90.

Gantier, M. P., McCoy, C. E., Rusinova, I., Saulep, D., Wang, D., Xu, D., et al. (2011). Analysis of microRNA turnover in mammalian cells following Dicer1 ablation. Nucleic Acids Res. 39, 5692-5703.

Gatenby, R. A., and Gillies, R. J. (2004) Why do cancers have high aerobic glycolysis? Nat. Rev. Cancer 4, 891-899.

Godlewski, J., Nowicki, M. O., Bronisz, A., Nuovo, G., Palatini, J., Lay, M. D., et al. (2010a). MircroRNA451 regulates LKB1/AMPK signaling and allows adaptation to metabolic stress in glioma cells. Mol. Cell 37, 620-632.

Godlewski, J., Newton, H. B., Chiocca E. A., and Lawler, S. E. (2010b). MicroRNAs and glioblastoma; the stem cell connection. Cell Death Differ. 17, 221-228.

Godlewski, J., Nowicki, M. O., Bronisz, A., Williams, S., Otsuki, A.
Nuovo, G., et al. (2008). Targeting of the Bmi-1 oncogene/stem cell renewal factor by microRNA128 inhibits glioma proliferation and self-renewal. Cancer Res. 68, 9125-9130.

Goldman, S., Levivier, M., Pirotte, B., Brucher, J. M., Wikler, D., Damhaut P., et al. (1996). Regional glucose metabolism and histopathology of gliomas. A study based on positron emission tomographyguided stereotactic biopsy. Cancer 78, 1098-1106.

Hardie, D. G. (2007). Ampactivated/snfl protein kinases: conserved guardians of cellular energy. Nat. Rev. Mol. Cell Biol. 8, 774-785.

Harpold, H. L., Alvord, E. C. Jr., and Swanson, K. R. (2007). The evolution of mathematical modeling of glioma proliferation and invasion. $J$. Neuropathol. Exp. Neurol. 66, 1-9.

Hatzikirou, H., Basanta, D., Simon, M., Schaller, K., and Deutsch, A. (2010). 'Go or grow': the key to the emergence of invasion in tumour progression? Math. Med. Biol. 27, 255-281.

Heiden, M. G., Cantley, L. C., and Thompson, C. B. (2009). Understanding the Warburg effect: the metabolic requirements of cell proliferation. Science 324, 1029-1033.

Hong, B., Wiese, B., Bremer, M., Heissler, H. E., Heidenreich, F., Krauss, J. K. et al. (2012). Multiple microsurgical resections for repeated recurrence of glioblastoma multiforme. Am. J. Clin. Oncol. (in press).

Ilina, O., Bakker, G., Vasaturo, A., Hofmann, R. M., and Friedl, P. (2011) Two-photon laser-generated microtracks in 3d collagen lattices: principles of MMP-dependent and independent collective cancer cell invasion. Phys. Biol. 8, 015010.

Jaalinoja, J., Herva, R., Korpela, M., Hoyhtya, M., and TurpeenniemiHujanen, T. (2000). Matrix metalloproteinase 2 (mmp-2) immunoreactive protein is associated with poor grade and survival in brain neoplasms. J. Neurooncol. 46, 81-90. 
Jacobs, V. L., Valdes, P. A., Hickey, W. F., and De Leo, J. A. (2011). Current review of in vivo gbm rodent models: emphasis on the cns-1 tumour model. ASN Neuro 3, e00063.

Jain, R. K. (1987). Transport of molecules in the tumor interstitium: a review. Cancer Res. 47, 3039-3051.

Jia, Y., Zeng, Z. Z., Markwart, S. M., Rockwood, K. F., Ignatoski, K. M., Ethier, S. P., et al. (2004). Integrin fibronectin receptors in matrix metalloproteinase-1-dependent invasion by breast cancer and mammary epithelial cells. Cancer Res. 64, 8674-8681.

Jones, R. G., and Thompson, C. B. (2009). Tumor suppressors and cell metabolism: a recipe for cancer growth. Genes Dev. 23, 537-548.

Kaufman, L. J., Brangwynne, C. P., Kasza, K. E., Filippidi, E., Gordon, V. D., Deisboeck, T. S., et al. (2005). Glioma expansion in collagen I matrices: analyzing collagen concentration-dependent growth and motility patterns. Biophys. J. 89, 635-650.

Kim, H. D., Guo, T. W., Wu, A. P., Wells, A., Gertler, F. B., and Lauffenburger, D. A. (2008). Epidermal growth factor-induced enhancement of glioblastoma cell migration in $3 \mathrm{~d}$ arises from an intrinsic increase in speed but an extrinsic matrix and proteolysis-dependent increase in persistence. Mol. Biol. Cell 19, 4249-4259.

Kim, J. W., and Dang, C. V. (2006). Cancer's molecular sweet tooth and the Warburg effect. Cancer Res. 66, 8927-8930.

Kim, Y., Lawler, S., Nowicki, M. O., Chiocca, E. A., and Friedman, A. (2009). A mathematical model of brain tumor: pattern formation of glioma cells outside the tumor spheroid core. J. Theor. Biol. 260, 359-371.

Kim, Y., Roh, S., Lawler, S., and Friedman, A. (2011a). miR451 and AMPK/mark mutual antagonism in glioma cells migration and proliferation. PLOS ONE 6:e28293. doi:10.1371/journal.pone.0028293

Kim, Y., Stolarska, M., and Othmer, H. G. (2011b). The role of the microenvironment in tumor growth and invasion. Prog. Biophys. Mol. Biol. 106, 353-379.

Kim, Y., Stolarska, M., and Othmer, H. G. (2007). A hybrid model for tumor spheroid growth in vitro I: theoretical development and early results. Math. Models Methods Appl. Sci. 17, 1773-1798.
Kudlow, J. E., Cheung, C. Y., and Bjorge, J. D. (1986). Epidermal growth factor stimulates the synthesis of its own receptor in a human breast cancer cell line. J. Biol. Chem. 261, 4134-4138.

Lamszus, K., Schmidt, N. O., Jin, L., Laterra, J., Zagzag, D., Way, D., et al. (1998). Scatter factor promotes motility of human glioma and neuromicrovascular endothelial cells. Int. J. Cancer 75, 19-28.

Lawler, S., and Chiocca, E. A. (2009). Emerging functions of microRNAs in glioblastoma. J. Neurooncol. 92, 297-306.

Li, C. K. (1982). The glucose distribution in 91 rat brain multicell tumor spheroids and its effect on cell necrosis. Cancer 50, 2066-2073.

Lowengrub, J. S., Frieboes, H. B., Jin, F., Chuang, Y. L., Li, X., MacKlin, P., et al. (2010). Nonlinear modelling of cancer: bridging the gap between cells and tumours. Nonlinearity 23, R1.

Luca, A. D., Niccolo Arena, Sena, L. M., and Medico, E. (1999). Met overexpression confers HGF-dependent invasive phenotype to human thyroid carcinoma cells in vitro. J. Cell. Physiol. 180, 365-371.

Lund-Johansen, M., Bjerkvig, R., Humphrey, P. A., Bigner, S. H., Bigner, D. D., and Laerum, O. D. (1990). Effect of epidermal growth factor on glioma cell growth, migration, and invasion in vitro. Cancer Res. 50, 6039-6044.

Pham, K., Chauviere, A., Hatzikirou, H., Li, X., Byrne, H. M., Cristini, V., et al. (2012). Density-dependent quiescence in glioma invasion: instability in a simple reaction-diffusion model for the migration/proliferation dichotomy. J. Biol. Dyn. 6(Suppl. 1), 54-71.

Platten, M., Wick, W., and Weller, M. (2001). Malignant glioma biology: role for TGF-beta in growth, motility, angiogenesis, and immune escape. Microsc. Res. Tech. 52, 401-410.

Preziosi, L., and Tosin, A. (2009). Multiphase and multiscale trends in cancer modelling. Math. Model. Nat. Phenom. 4, 1-11.

Preziosi, L., and Vitale, G. (2011). A multiphase model of tumor and tissue growth including cell adhesion and plastic reorganization. Math. Models Methods. Appl. Sci. 21, 1901-1932.

Rejniak, K. A., and Anderson, A. R. A. (2011). Hybrid models of tumor growth. Wiley Interdiscip. Rev. Syst. Biol. Med. 3, 115-125.

Rejniak, K. A., and McCawley, C. J. (2010). Current trends in mathematical modeling of tumor microenvironment interaction: a survey of tools and applications. Exp. Biol. Med. 235, 411-423.

Rong, Z., Cheema, U., and Vadgama, P. (2006). Needle enzyme electrode based glucose diffusive transport measurement in a collagen gel and validation of a simulation model. Analyst 131, 816-821.

Rozental, J. M., Levine, R. L., and Nickles, R. J. (1991). Changes in glucose uptake by malignant gliomas: preliminary study of prognostic significance. J. Neurooncol. 10 , 75-83.

Sadlonova, A., Novak, Z., Johnson, M. R., Bowe, D. B., Gault, S. R., Page, G. P., et al. (2005). Breast fibroblasts modulate epithelial cell proliferation in three-dimensional in vitro co-culture. Breast Cancer Res. 7, R46-R59.

Saffarian, S., Collier, I. E., Marmer, B. L., Elson, E. L., and Goldberg, G. (2004). Interstitial collagenase is a Brownian ratchet driven by proteolysis of collagen. Science 306 , 108-111.

Sampetrean, O., Saga, I., Nakanishi, M., Sugihara, E., Fukaya, R., Onishi, N., et al. (2011). Invasion precedes tumor mass formation in a malignant brain tumor model of genetically modified neural stem cells. Neoplasia 13 , 784-791.

Sander, L. M., and Deisboeck, T. S. (2002). Growth patterns of microscopic brain tumors. Phys. Rev. E Stat. Nonlin. Soft Matter Phys. 66, 051901.

Scianna, M., Merks, R. M., Preziosi, L., and Medico, E. (2009). Individual cell-based models of cell scatter of ARO and MLP-29 cells in response to hepatocyte growth factor. J. Theor. Biol. 260, 151-160.

Sen, S., Dong, M., and Kumar, S. (2009). Isoform-specific contributions of a-actinin to glioma cell mechanobiology. PLoS ONE 4:e8427. doi:10.1371/journal.pone.0008427

Silbergeld, D. L., and Chicoine, M. R. (1997). Isolation and characterization of human malignant glioma cells from histologically normal brain. J. Neurosurg. 86, 525-531.

Stein, A. M., Demuth, T., Mobley, D., Berens, M., and Sander, L. M. (2007). A mathematical model of glioblastoma tumor spheroid invasion in a three-dimensional in vitro experiment. Biophys. J. 92, 356-365.

Stella, M. C., and Comoglio, P. M. (1999). HGF: a multifunctional growth factor controlling cell scattering. Int. J. Biochem. Cell Biol. 31, 1357-1362.

Stylli, S. S., Kaye, A. H., MacGregor, L., Howes, M., and Rajendra, P. (2005). Photodynamic therapy of high grade glioma - long term survival. J. Clin. Neurosci. 12, 389-398.

Swanson, K. R., Alvord, E. C., and Murray, J. D. (2003). Virtual resection of gliomas: effect of extent of resection on recurrence. Math. Comput. Model. 37, 1177-1190.

Tamagnone, L., and Comoglio, P. M. (1997). Control of invasive growth by hepatocyte growth factor (hgf) and related scatter factors. Cytokine Growth Factor Rev. 8, 129-142.

Thorne, R. G., Hrabetova, S., and Nicholson, C. (2004). Diffusion of epidermal growth factor in rat brain extracellular space measured by integrative optical imaging. J. Neurophysiol. 92, 3471-3481.

Trusolino, L., and Comoglio, P. M. (2002). Scatter-factor and semaphorin receptors: cell signalling for invasive growth. Nat. Rev. Cancer 2, 289-300.

Valle-Casuso, J. C., Gonzalez-Sanchez, A., Medina, J. M., and Tabernero A. (2012). HIF-1 and c-Src mediate increased glucose uptake induced by endothelin-1 and connexin43 in astrocytes. PLOS ONE 7:e32448. doi:10.1371/journal.pone. 0032448

Warburg, O. (1956). On the origin of cancer cells. Science 123, 309-314.

Watters, J. J., Schartner, J. M., and Badie, B. (2005). Microglia function in brain tumors. J. Neurosci. Res. 81, 447-455.

Wiranowska, M., and Rojiani, M. V. (2011). "Extracellular matrix microenvironment in glioma progression," in Glioma - Exploring Its Biology and Practical Relevance, ed. Dr. Anirban Ghosh (Shanghai: InTech), 257-284.

Wolf, K., Wu, Y., Liu, Y., Geiger, J., Tam, E., Overall, C., et al. (2007). Multi-step pericellular proteolysis controls the transition from individual to collective cancer cell invasion. Nat. Cell Biol. 9, 893-904. 
Xu, R. H., Pelicano, H., Zhou, Y., Carew, J. S., Feng, L., Bhalla, K. N., et al. (2005). Inhibition of glycolysis in cancer cells: a novel strategy to overcome drug resistance associated with mitochondrial respiratory defect and hypoxia. Cancer Res. 65, 613-621.

Young, N., and Brocklyn, J. R. (2007). Roles of sphingosine-1-phosphate (S1P) receptors in malignant behavior of glioma cells. Differential effects of S1P2 on cell migration and invasiveness. Exp. Cell Res. 313, 1615-1627.

Zhou, Y., Larsen, P. H., Hao, C., and Yong, V. W. (2002). Cxcr4 is a major chemokine receptor on glioma cells and mediates their survival. J. Biol. Chem. 277, 49481-49487.

Conflict of Interest Statement: The authors declare that the research was conducted in the absence of any commercial or financial relationships that could be construed as a potential conflict of interest.

Received: 12 December 2012; accepted: 28 February 2013; published online: 18 March 2013.

Citation: Kim Y (2013) Regulation of cell proliferation and migration in glioblastoma: new therapeutic approach. Front. Oncol. 3:53. doi: 10.3389/fonc.2013.00053
This article was submitted to Frontiers in Molecular and Cellular Oncology, a specialty of Frontiers in Oncology.

Copyright $\odot 2013 \mathrm{Kim}$. This is an openaccess article distributed under the terms of the Creative Commons Attribution License, which permits use, distribution and reproduction in other forums, provided the original authors and source are credited and subject to any copyright notices concerning any third-party graphics etc. 


\section{A. APPENDIX}

\section{A.1. PARAMETER ESTIMATION AND NON-DIMENSIONALIZATION}

\section{A.1.1. Tumor module}

The characteristic distance is the maximum domain size ( $L=2 \mathrm{~mm}$ ) of growing glioblastoma within $48 \mathrm{~h}$ similar to the size of the migratory region in the experiments by Godlewski et al. (2010a) and we use $T=1 \mathrm{~h}$ to get dimensionless variables and parameters:

$$
\begin{gathered}
\bar{t}=\frac{t}{T}, \bar{x}=\frac{x}{L}, \bar{G}=\frac{G}{G^{*}}, \bar{C}=\frac{C}{C^{*}}, \bar{\rho}=\frac{\rho}{\rho^{*}}, \bar{P}=\frac{P}{P^{*}}, \\
\bar{D}_{G}=\frac{T}{L^{2}} D_{G}, \bar{D}_{C}=\frac{T}{L^{2}} D_{C}, \\
\bar{D}_{P}=\frac{T}{L^{2}} D_{P}, \bar{\lambda}_{i n}^{G}=\frac{T \lambda_{i n}^{G}}{G^{*}}, \bar{\lambda}_{b}=\frac{T \lambda_{b}}{G^{*}}, \bar{\lambda}_{c}=\frac{T \lambda_{c}}{G^{*}}, \\
\bar{\lambda}_{i n}^{C}=\frac{T \lambda_{i n}^{C}}{G^{*}}, \bar{\lambda}_{1}=T \lambda_{1} P^{*}, \\
\bar{\lambda}_{2}=T \lambda_{2}, \bar{\rho}_{*}=\frac{\rho_{*}}{\rho^{*}}, \bar{\lambda}_{3}=T \lambda_{3}, \bar{\mu}_{G}=T \mu_{G}, \\
\bar{\mu}_{C}=T \mu_{C}, \bar{\mu}_{P}=T \mu_{P},
\end{gathered}
$$

We estimate some of parameters and reference values in the following. (i) $D_{G}$ : diffusion coefficients of glucose $(G)$ were measured to be $6.7 \times 10^{-7} \mathrm{~cm}^{2} / \mathrm{s}$ in the brain (Jain, 1987) and $1.3 \times 10^{-6} \mathrm{~cm}^{2} / \mathrm{s}$ in collagen gel (Rong et al., 2006). We take $D_{G}=6.7 \times 10^{-7} \mathrm{~cm}^{2} / \mathrm{s}$ as in Jain (1987). (ii) $D_{P}$ : in experiments of the movement of MMP-1in the collagen fibril, Saffarian et al. (2004) estimated the diffusion coefficient of MMPs as $(8.0 \pm 1.5) \times 10^{-9} \mathrm{~cm}^{2} / \mathrm{s}$ for inactive mutant and $(8.0 \pm 1.5) \times 10^{-9} \mathrm{~cm}^{2} / \mathrm{s}$ for wild-type activated MMP-1, respectively. For our simulation, we take $D_{P}=8.0 \times 10^{-9} \mathrm{~cm}^{2} / \mathrm{s}$. (iii) $D_{C}$ : the diffusion coefficient of chemoattractant was taken from one of EGF, $D_{C}=1.66 \times 10^{-6} \mathrm{~cm}^{2} / \mathrm{s}$ from Thorne et al. (2004). (iv) $\lambda_{c}$ (glucose consumption rate): the measured level $\alpha=1.6 \mathrm{pg} / \mathrm{cell} / \mathrm{min}$ for piecewise increasing linear consumption term $\alpha(G) n$ was used in a glioma invasion study (Sander and Deisboeck, 2002) along with a threshold value $G_{1}^{t h}=2.0 \times 10^{-4} \mathrm{~g} / \mathrm{cm}^{3}$, taken from the work of $\mathrm{Li}$ (1982). We take $\lambda_{c}=0.8 \mathrm{pg} / \mathrm{cell} / \mathrm{min}$ and use a sphere with a radius $r=8-20 \mu m$ for estimation of cell volume. (v) $G^{*}$ : Sander and Deisboeck (2002) used the characteristic concentration of glucose $2 \times 10^{-4} \mathrm{~g} / \mathrm{cm}^{3}$, and took the value $6 \times 10^{-4} \mathrm{~g} / \mathrm{cm}^{3}$ for glucose level far from the tumor (see also Deisboeck et al., 2001). Kim et al. (2009) took $6 \times 10^{-4} \mathrm{~g} / \mathrm{cm}^{3}$ as a reference value based on experimental observation. In in vitro experimental study (Godlewski et al., 2010a), high $\left(4.5 \mathrm{~g} / \mathrm{l}=4.5 \times 10^{-3} \mathrm{~g} / \mathrm{cm}^{3}\right)$ and low $\left(0.3 \mathrm{~g} / \mathrm{l}=3.0 \times 10^{-4} \mathrm{~g} / \mathrm{cm}^{3}\right)$ levels of glucose induced the up- and down-regulated miR-451 expression. We take the high glucose level, $G^{*}=4.5 \times 10^{-3} \mathrm{~g} / \mathrm{cm}^{3}$, as a reference value. (vi) $\rho^{*}$ : collagen is one of main ECM components. ECM concentration was estimated to be $0.5-2.0 \mathrm{mg} / \mathrm{ml}$ in an experimental study of growth patterns of glioma spheroids. Stein et al. (2007) investigated growth patterns of glioma cell lines in experiments where U87 wild-type and its mutant, U87DEGFR, were implanted into collagen I of concentration of $2.6 \mathrm{mg} / \mathrm{ml}$. We take $\rho^{*}=1.0 \mathrm{mg} / \mathrm{cm}^{3}$ as our reference value of ECM. (vii) $P^{*}:$ in a breast cancer cell invasion study, MMP concentrations were measured to be $1.6 \times 10^{-9} \mathrm{~g} / \mathrm{cm}^{3}$ (Jia et al., 2004). On the other hand, it was shown that PCK3145 can down-regulate MMP9 level in prostate cancer patients with up-regulated MMP-9 level of $>100 \mu \mathrm{g} / \mathrm{l}$ (Annabi et al., 2005). We take the high levels of MMPs $\left(P^{*}=100 \mu \mathrm{g} / \mathrm{l}\right)$ as our reference value of MMPs.

Table 1 lists reference values and all parameter values above.

\section{A.1.2. Core control system (miR-451, AMPK)}

We use the following dimensionalization scheme to get the dimensionless key control parameters (Kim et al., 2011a).

$$
\begin{gathered}
\tau=\mu_{1} t, M=\frac{m}{m^{*}}, A=\frac{a}{a^{*}}, G=\frac{g}{m^{*}}, l_{g}=\frac{\Lambda_{g}}{\mu_{1}}, \\
S=\frac{s}{\mu_{2} a^{*}}, l_{1}=\frac{\Lambda_{1} \Lambda_{2}^{2}}{\mu_{1} m^{*}}, l_{2}=\Lambda_{2}, \\
l_{3}=\frac{\Lambda_{3} \Lambda_{4}^{2}}{\mu_{2} a^{*}}, l_{4}=\Lambda_{4}, \alpha=\Lambda_{5}\left(a^{*}\right)^{2}, \\
\beta=\Lambda_{6}\left(m^{*}\right)^{2}, \epsilon=\frac{\mu_{1}}{\mu_{2}},
\end{gathered}
$$

\begin{tabular}{|c|c|c|c|}
\hline & Description & Value & Refs. \\
\hline$l_{g}$ & Glucose signaling rate & 1.0 & Kim et al. (2011a) \\
\hline$I_{1}$ & $\begin{array}{l}\text { Autocatalytic production rate } \\
\text { of miR-451 }\end{array}$ & 4.0 & Kim et al. (2011a) \\
\hline $1 / 2$ & Hill-type coefficient & 1.0 & Kim et al. (2011a) \\
\hline$\alpha$ & $\begin{array}{l}\text { Inhibition strength of miR-451 } \\
\text { by AMPK complex }\end{array}$ & 1.6 & Kim et al. (2011a) \\
\hline$t h_{M}$ & $\begin{array}{l}\text { Threshold of AMPK for } \\
\text { proliferation/migration switch }\end{array}$ & 2.0 & Estimated \\
\hline 13 & $\begin{array}{l}\text { Autocatalytic production rate } \\
\text { of AMPK }\end{array}$ & 4.0 & Kim et al. (2011a) \\
\hline$/ 4$ & Hill-type coefficient & 1.0 & Kim et al. (2011a) \\
\hline$\beta$ & $\begin{array}{l}\text { Inhibition strength of AMPK } \\
\text { complex by miR- } 451\end{array}$ & 1.0 & Kim et al. (2011a) \\
\hline$S$ & Signaling source of AMPK & 0.2 & Kim et al. (2011a) \\
\hline$\epsilon$ & $\begin{array}{l}\text { Scaling factor (slow } \\
\text { dynamics) of AMPK complex }\end{array}$ & 0.02 & $\begin{array}{l}\text { Crute et al. (1998); } \\
\text { Aguda et al. (2008); } \\
\text { Gantier et al. (2011); } \\
\text { Kim et al. (2011a) }\end{array}$ \\
\hline$t h_{A}$ & Threshold of AMPK for & 2.0 & Estimated \\
\hline
\end{tabular}

and the dimensionless form of core control system

$$
\begin{aligned}
& \frac{d M}{d \tau}=l_{g} G+\frac{l_{1}}{l_{2}^{2}+\alpha A^{2}}-M, \\
& \epsilon \frac{d A}{d \tau}=S+\frac{l_{3}}{l_{4}^{2}+\beta M^{2}}-A .
\end{aligned}
$$

Table A1 | Parameters that are used in the intracellular miR-451-AMPK system.

proliferation/migration switch 